\title{
The influence of permeability on the erosion rate of fine-grained marine sediments
}

\author{
Henning Mohr ${ }^{1}$, Postdoctoral Fellow, PhD \\ Scott Draper ${ }^{2}$, Associate Professor, PhD \\ David J. White ${ }^{3}$, Professor, PhD \\ Liang Cheng ${ }^{4}$, Professor, $\mathrm{PhD}$
}

\section{ABSTRACT}

Laboratory experiments have been carried out to investigate the erosion behaviour of a number of marine sediments which were reconstituted and sieved in various ways to ensure a large variation in soil properties such as (i) particle size distribution (including median grain size and fines content), (ii) bulk density, and (iii) hydraulic permeability. Based on the experimental results, it was found that for finer marine sediments the erosion rate at a given shear stress was sensitive to changes in these soil properties. No unique relationship was found between changes in the erosion rate and changes in the bulk density or fines content. More specifically, we find that the erosion rate at a given shear stress reduces with increases in density and fines content, but by an amount that is different for different sediments. In contrast, we show that there appears to be a unique relationship between permeability and erosion rate, such that permeability may be used to predict the erosion rate for the marine sediments at any density. By reinterpreting existing experimental results in the literature, we find that this same relationship between permeability and erosion rate is apparent for quartz sediments. We propose an empirical relationship, which fits well the erosion rate behaviour of finer sediments close to the threshold shear stress.

\footnotetext{
${ }^{1}$ Centre for Offshore Foundation Systems, The University of Western Australia, 35 Stirling Highway, Crawley, WA 6009, Australia. E-mail: henning.mohr@uwa.edu.au.

${ }^{2}$ School of Civil, Environmental and Mining, The University of Western Australia, 35 Stirling Highway, Crawley, WA 6009, Australia. E-mail: scott.draper@uwa.edu.au.

${ }^{3}$ University of Southampton, University Road, Southampton, SO17 1BJ, United Kingdom. E-mail: david.white@soton.ac.uk.

${ }^{4}$ School of Civil, Environmental and Mining, The University of Western Australia, 35 Stirling Highway, Crawley, WA 6009, Australia. E-mail: liang.cheng@uwa.edu.au.
} 


\section{INTRODUCTION}

Many subsea structures are installed on the seabed, such as pipelines and subsea foundations. For each of these structures near bed currents, due to periodic tides, internal waves and tropical storms may cause a local increase of sediment transport capacity. This can lead to local scour of seabed sediments and, in turn, result in self-burial or settlement of structures without scour protection. Leckie et al. (2015), for example, has recently summarised scour and settlement observations of a pipeline on the North West Shelf (NWS) of Australia. Many subsea structures are installed on the seabed, such as pipelines and subsea foundations.

Due to the effect of scour on structures, the erosional behaviour of natural subsea sediments must be quantified to ensure safety, reduce environmental risk and optimise infrastructure investment. This is particularly challenging in locations such as the NWS of Australia, where the sediments are biogenic, well sorted, angular, and they exhibit large density variations and erosion behaviour that potentially differs from classical predictions. These characteristics make them different to the uniform, sand-sized sediments that have been the focus of most classical sediment transport studies (Shields 1936; Miller et al. 1977; Soulsby 1997).

Generally, sediment erosion properties are summarised in terms of (i) the critical condition for initiation of erosion (i.e. the threshold shear stress) and (ii) the erosion rate as a function of the excess shear stress (McCave 1984). Differences in the threshold shear stress of NWS sediments, compared with uniform silica sand, have been reported by Mohr et al. (2013) and Mohr (2015). These results showed that particle size and grain density measurements are insufficient to isolate the threshold shear stress for NWS sediments. Mohr (2015) showed that the density and particle size distribution influence the initiation of movement, whereas for fine-grained marine sediments the erosion threshold appear to be higher (McCave 1984; Winterwerp and van Kesteren 2004), indicating a dependence on the content on finer sediment. Based on the collection of results available in the literature, the erosion threshold is often related empirically to bulk density and fines (or clay) content. For example, Roberts et al. (1998) investigated the erosion behaviour of quartz particles showing for fine-grained sediments a rapid decrease in erosion rate as the bulk density increases. 
They also concluded from their experiments that a reduction in particle size results in a decrease in erosion rate. The latter finding is also in agreement with the experiments of Torfs (1995) using montmorillonite and kaolinite mixtures. However, none of these parameters consistently captures the erosion properties across all sediment types (McCave 1984; Mohr 2015). Furthermore, limited studies have focused on the erosion rate of fine-grained marine sediments that are of calcareous nature similar to the ones investigated in this study. The few studies investigating these type of sediments such as calcareous ooze (Southard et al. 1971) and clay (Lonsdale and Southard 1974) focus mostly on the initiation of motion. Hence, the relationship between the erosion rate of fine-grained marine sediment (in particular calcareous NWS sediments) and their basic soil characteristics is poorly understood.

Motivated by this finding, the main aim of this paper is to investigate how the underlying characteristics of marine sediments affect their erosion rate as a function of shear stress. In the underlying experiments, soil properties including bulk density, particle size distribution and permeability were measured concurrently with erosion testing, so as to systematically explore how these characteristics affect the erosion rate. Comparisons are made with existing literature throughout.

\section{SEDIMENTS USED IN THIS STUDY}

Three different marine sediments from the NWS of Australia have been used in this study comprising a silty SAND (referred to as NWS1), a very silty SAND (referred to as NWS2) and a sandy SILT (referred to as NWS3). These sediments are principally composed of small shell fragments and residues from marine fauna, with little terrigenous material (see Mohr et al. 2013). The particle size distribution of each sediment is given in Fig. 1. To explore the erosion rate trends of these sediments, the bulk density and the grain size distribution of each sediment has been systematically changed affecting simultaneously their permeability. The approach is similar to that often taken in exploring artificial sand/mud mixtures (e.g. Mitchener et al. 1996; Panagiotopoulos

et al. 1997; Jacobs et al. 2011; Roberts et al. 1998) except that in this case natural sediments are used and permeability is investigated as a separate parameter.

For each type of sediment, samples with different density were prepared. This was achieved 
by mixing the sediments with different measured quantities of water to form a homogenous slurry or paste. The samples were then poured into a sample holder and allowed to consolidate under various consolidation stresses. Density measurements were made by subsampling.

To assist interpretation of the experiments, two artificial silica sands (referred to throughout as SS1 and SS2) were also tested which are uniformly-graded (see Fig. 1). Details on all the tested sediments can be found in Table 1 .

\section{EXPERIMENTAL DESIGN}

The erosion properties of the sediments were investigated in a recirculating annular flume, operated at the University of Western Australia. As shown in Fig. 2, the flume provides a rectangular test section $(200 \mathrm{~mm} \times 200 \mathrm{~mm} \times 1800 \mathrm{~mm})$ in which the sediments are exposed to a constant flow velocity provided by an axial flow pump (Mohr et al. 2016a).

The working section of the MOT has a recess hole that can accommodate a sediment sample prepared in a semi-cylindrical holder. The sample surface occupies a rectangular plan area of $150 \mathrm{~mm} \times 72 \mathrm{~mm}$; see Mohr (2015). The surface profile of the sample (i.e. the height of the sample across its plan area) is recorded using a 3-D laser scanner. Flow velocity was measured with an Acoustic Doppler Velocimeter (ADV) Profiler over a region $35 \mathrm{~mm}$ above the bed at a location just upstream of the sample. The sampling frequency was $50 \mathrm{~Hz}$. The mean velocities measured with the ADV are transformed to shear stresses by assuming a logarithmic velocity distribution close to the test bed and the empirical fit of the seabed roughness length $\left(z_{0}\right)$ of Christoffersen and Jonsson (1985) based on Nikuradse (1933)'s experimental data (see Mohr 2015 for more details). Complementary information regarding the actual measurements, the shear stress calculation and hydrodynamic conditions within the working section of the MOT such as flow patterns or pressure distributions are described by Mohr et al. (2016a).

To investigate the erosion behaviour, a sample was exposed to constant levels of shear stress for a period of 3 minutes, in increments of velocity of $\sim 0.04 \mathrm{~m} / \mathrm{s}$ measured $35 \mathrm{~mm}$ above the seabed. The erosion depth over the whole sample plan area was measured using the 3-D laser scanner. During the tests scanning was performed at a frequency of $0.1 \mathrm{~Hz}$ to measure the erosion depth 
rate regularly, or at intervals of 30-60 seconds if the turbidity was too large for more frequent scanning.

For each of the sediments, the threshold shear stress for erosion was defined as the shear stress increment at which the erosion rate first (and consistently) exceeded $10^{-7} \mathrm{~m} / \mathrm{s}$. Defining the shear stress in terms of an erosion rate in this way is relatively common (see, for example, Roberts et al. 1998 or Buffington and Montgomery 1997 for an overview). The dimensionless bedload transport rate associated with an erosion rate of $10^{-7} \mathrm{~m} / \mathrm{s}$ is approximately between $10^{-4}$ to $10^{-3}$ for the sandy samples. This range in transport rate is consistent with that adopted by Smith and Cheung (2004) and is consistent with the definition of weak transport from early studies by Kramer (1935). Additionally based on our definition, the threshold shear stress estimates for the silica sands used in this study were in very good agreement with the well-known Shields curve shown in Fig. 3 (see also Mohr 2015). In the subsequent analysis, this threshold shear stress (associated with the

erosion rate of $10^{-7} \mathrm{~m} / \mathrm{s}$ ) is generally defined as $\tau_{\mathrm{cr}}$, whereas the threshold shear stress obtained from the Shields curve is noted as $\tau_{\mathrm{cr}}^{*}$.

The erosion rate was calculated at different levels of shear stress from the change in the surface height of the sample (averaged over the plan area of the sample) divided by the duration that the shear stress was applied (i.e. 3 minutes). Additional steady shear stress tests were carried out for each sample type where the erosion rate was initially constant, but began to reduce with depth due to hydrodynamic shielding of the sample or an increase in erosion resistance with depth. To avoid any influence of depth dependent effects on the erosion rate, erosion rates were only calculated from the top layer of the sample where the erosion rate was known to be constant.

\section{EXPERIMENTAL RESULTS}

Following erosion testing on all the samples, the threshold shear stress was determined and then compared with the well-known Shields curve (including the empirical fit given by Soulsby and Whitehouse 1997). The threshold shear stress has been made non-dimensional according to

$$
\theta_{\mathrm{cr}}=\frac{\tau_{\mathrm{cr}}}{\rho g\left(G_{s}-1\right) d_{50}}
$$


where $\theta_{\text {cr }}$ is threshold Shields parameter, $\tau_{\text {cr }}$ is the threshold shear stress, $\rho$ is the water density (taken to be $1000 \mathrm{~kg} / \mathrm{m}^{3}$ throughout), $g$ is the acceleration due to gravity, $G_{s}$ is the relative density of the sediment and $d_{50}$ is the average particle size. The grain size has been made non-dimensional according to

$$
D_{*}=\left[\frac{g\left(G_{s}-1\right)}{\nu^{2}}\right]^{1 / 3} d_{50},
$$

where $\nu$ is fluid viscosity (taken to be $1 \times 10^{-6} \mathrm{~m} / \mathrm{s}^{2}$ throughout).

In each of the erosion rate experiments for the sediments, we have chosen to compare with the empirical formula due to Yalin (1963), which has been shown to agree well with experimental data compared to other bedload equations (see Wiberg and Smith 1989). Yalin's expression after Soulsby (1997) is given as

$$
\Phi=F_{Y} \theta^{0.5}\left(\theta-\theta_{\text {cr }}\right)
$$

with

$$
\begin{gathered}
F_{Y}=\frac{0.365}{\theta_{\mathrm{cr}}}\left[1-\frac{1}{a} \ln (1+a)\right], \\
a=2.45 \theta_{\mathrm{cr}}^{-0.5} G_{s}^{-0.4}\left(\theta-\theta_{\mathrm{cr}}\right) .
\end{gathered}
$$

To compare these bedload transport rates with the measured erosion rates for the sediments, the bedload rate can be made dimensional according to

$$
q_{b}=\Phi\left[g\left(G_{s}-1\right) d_{50}^{3}\right]^{1 / 2}
$$

where $q_{b}$ is the volumetric bedload transport rate and $\Phi$ is the dimensionless bedload transport rate.

The bedload rate can then, finally, be expressed as an erosion rate using the following expression 


$$
\eta=\frac{q_{b}}{(1-\epsilon) L}
$$

where $\epsilon$ is the porosity, $L$ is the sample length (in this study, $L=150 \mathrm{~mm}$ ) and $\eta$ is the (apparent)

erosion rate. Similar approaches relating the bedload rate to the erosion rate are presented in Nairn (1998), Ye (2012) and Mohr et al. (2016b).

Additional erosion experiments were carried out for two uniform silica sediments (see Fig. 1 for the particle size distribution) to investigate the suitability of the above conversion and Yalin's bedload transport formula. As shown in Fig. 3, good agreement was found between the experimental results and Yalin's bedload transport formula and data from Gilbert and Murphy (1914) and Wilson (1966) taken from Soulsby (1997).

\subsection{Varying bulk density}

To investigate the effect of bulk density, erosion testing was also conducted on the three NWS sediments with their natural fines content (i.e. without sieving). The properties of these natural sediments are listed in Table 1. Table 2 presents additional details for these sediments prepared at different density, and includes measurements of the threshold shear stress and erosion rate parameters obtained from the erosion tests.

To allow interpretation, the results for threshold shear stress are presented in Fig. 4. It can be seen in this figure that as the fines content increases the threshold shear stress increases (i.e. they plot higher above the empirical Shields curve), with the difference to the Shields curve becoming more pronounced with increased density. The increase with density is largest for NWS3-T1, which has the highest natural fines content.

Across all of the erosion testing for the sediments in Table 2, the erosion results from the step tests have been fitted to a general erosion formula of the form

$$
\eta=M\left(\tau-\tau_{\mathrm{cr}}^{*}\right)^{n}
$$

where $M$ and $n$ are fitting parameters, $\tau$ is the applied bed shear stress and $\tau_{\mathrm{cr}}^{*}$ is the threshold bed 
shear stress obtained from the Shields curve based on the median grain size. This threshold was chosen in the expectation that erosion can occur as soon as gravitational forces are exceeded.

The form of Eq. (6) is similar to that suggested by Roberts et al. (1998), Winterwerp and van Kesteren (2004) and Whitehouse et al. (2000). For context, the range in $n$ reported by Roberts et al. (1998) for coarse quartz sediments was 1.6 (for $d_{50}=1.35 \mathrm{~mm}$ ) to 2.2 (for $d_{50}=0.222 \mathrm{~mm}$ ). Although it should be noted that their definition of critical shear stress is slightly different to that in Eq. (6).

The fitted curves based on Eq. (6) are shown in Fig. 5 for each of the NWS sediments together with the measurements from erosion step tests. Also shown on these figures are the empirical bedload transport rates due to Yalin (1963), computed based on the threshold shear stress from the Shields curve and converted to an equivalent erosion rate using Eq. (5). Comparison to this empirical formula shows that it typically gives poor agreement for NWS3-T1 and NWS2-T1 at higher density. For NWS1-T1 and NWS2-T1 at low density the empirical formula gives more reasonable agreement and was consistent with observations of more significant bedload transport for these samples.

In Fig. 5 it is clear that the erosion rate reduces, for a given shear stress, as the density of the sample increases. This trend is most pronounced for NWS2-T1 and NWS3-T1, which have more fines content. For instance, assuming a constant shear stress, comparison of the medium density sample of NWS2-T1 to the lowest density indicates a difference in erosion rate of an order of magnitude at a shear stress of $0.5 \mathrm{~Pa}$.

The fitted parameters $M$ and $n$ are listed in Table 2 for each of the sediments. It can be seen that $n$ varies over a similar range to that presented by Roberts et al. (1998), and shows less variation than the coefficient $M$. To explore the variation in $M$, Fig. 6 is a plot of this parameter as a function of density for each of the sediments. It can be seen that $M$ appears to be a linear function of density but that the slope of the linear line is different for the different sediments. The line is steep for sediment with a higher percentage of fines such as NWS2-T1 and NWS3-T1 and is close to zero for the coarsest sediment (NWS1-T1). Similar trends to that shown in Fig. 6 have 
been given by Roberts et al. (1998) for quartz sediments. Therefore, in summary, it is clear that density alters the erosion rate for marine sediments with high fines content, but by an amount that is different for different sediment.

In addition to the quantitative erosion rate differences in Fig. 6, the density of the sample was found in the experiments on NWS2-T1 to alter the mode of erosion. At the smallest density of $1830 \mathrm{~kg} / \mathrm{m}^{3}$, for example, the NWS2-T1 sediment moved mostly in bedload transport exhibiting a similar erosion rate to that predicted based on Yalin (1963). In contrast, at higher densities the threshold shear stresses increased significantly and the particles were taken into suspension at shear stresses above threshold.

\subsection{Varying fines content}

The fines ${ }^{1}\left(\right.$ or clay $\left.^{2}\right)$ content is often described as having a decisive effect on the threshold shear stress, causing the erosion rate to decrease once the fines (or clay) content increases (see for example Roberts et al. 1998). To investigate this expectation, a total of 8 erosion experiments were performed on NWS2-T2 and NWS3-T2 sediments with varying levels of fines content (listed in Table 3). The PSDs for these sediments were manipulated by separating the fines from the coarse fraction, and then recombining them to form mixtures with fines percentages of $0,18,30,50$ and 100 for NWS2-T2 and 0, 39 and 100 for NWS3-T2. NWS2-T2 has a ratio of clay to silt-sized particles of 0.15 and NWS3-T2 of 0.21 (hence the clay content ranges from $0-18 \%$ for NWS2-T2 and $0-21 \%$ for NWS3-T2). Testing was not conducted on NWS1 as the natural fines content was small.

For all the sediments in Table 3, samples were prepared in a way to try and ensure changes in the fines content were the main variable leading to changes in erosion rate. An erosion test was conducted for each sample and the resulting erosion rate was fitted to Eq. (6).

Fig. 7 presents the non-dimensional threshold shear stress for each of the mixed sediments (with tabulated values given in Table 3). At low fines content, the NWS sediments show similar values to the Shields prediction and lie within the scatter band of previous data for uniform sands.

\footnotetext{
${ }^{1}$ Percentage of particles $<75 \mu \mathrm{m}$ for present study ( $<63 \mu \mathrm{m}$ after British Standard)

${ }^{2}$ Percentage of particles $<2 \mu \mathrm{m}$
} 
However, with decreasing median grain size due to increasing fines, the dimensionless threshold parameter increases above the Shields curve.

The erosion rates for the sediments in Table 3 are plotted in Fig. 8. It can be seen that with increasing fines/clay content the erosion rate decreases. This is reflected by the decrease of $M$ and $n$ in Table 3; the parameter $M$ again varying significantly more than $n$.

Fig. 9 is a plot of the variation in the parameter $M$ for each of the sediments in Table 3 , as a function of fines content. Even though the density is not kept constant across the samples in Table 3 (because keeping the density the same is difficult to achieve), the value of $M$ decreases consistently in Fig. 9 with fines content. This suggests that the fines/clay content appears to be the dominating factor for these sediments.

Across all of the results in Fig. 9, the value of $M$ can be seen to drop suddenly for NWS2-T2 at between $30 \%$ and 50\% fines content, whilst it drops for NWS3-T2 at between 0\% and 39\% fines content. It should also be noted that the density of the samples in Fig. 9 are slightly different, with a trend of reducing density with fines content (see Table 3). This reinforces the fact that the fines content is controlling the reduction in $M$ because the reduced density at the higher fines contents would be expected to have the reverse effect on $M$.

In summary, it is clear that the erosion rate of the sediments (as indicated by changes in the parameter $M$ ) is dependent on the fines content. However, the relationship between the fines content and $M$ is different for NWS2-T2 compared with NWS3-T2 and so, as in the case of density, the relationship is dependent on the sediment type.

\section{DISCUSSION}

The erosion rate properties of marine sediments recovered from the NWS of Australia have been examined in this paper. The particle size distribution has been manipulated by changing the fines content from $0 \%$ to $100 \%$, while the bulk density has been varied from approximately 1624 to $1971 \mathrm{~kg} / \mathrm{m}^{3}$. Collectively, it has been shown that the erosion behaviour is similar to that implied by classical empirical formulas for sand when the marine sediments have no limited fines content. However, for finer sediments changes in the fines content and the bulk density then lead to changes 
in the erosion rate and the mode of erosion.

To understand how bulk density and fines content collectively affect the threshold shear stress, Fig. 10 presents all of the erosion data from the sediments in Table 2 and Table 3 . In this figure, it appears that there is a particular fines content at which the sediment erosion rate starts to reduce significantly (i.e. by an order of magnitude in terms of the parameter $M$ ). The particular fines content at which this transition occurs appears to depend on the sediment type and the density of the sediment. For instance, as shown in Figure 10, the erosion rate reduces significantly when the fines content reaches somewhere between 30 and 50\% for NWS2-T2 at a bulk density of around $1800 \mathrm{~kg} / \mathrm{m}^{3}$, whilst for NWS3-T2 a significant reduction occurs with a fines content of $38 \%$ at a bulk density of $1700 \mathrm{~kg} / \mathrm{m}^{3}$. Additionally, looking at the variation in erosion rate for NWS2T1 and NWS3-T1 due to changes in density (indicated by the vertical range in values shown in Figure 10 for these sets of data points), it can be seen that the variation in erosion rate with fines content depends on the density. Hence, the results show that the density and fines content effect erosion rate in a coupled manner for each sediment (i.e. the density and fines content cannot independently indicate the erosion properties and their correlations to erosion rate are different for different sediments).

The particular fines content at which this transition occurs reduces as the density of the sediment increases. For instance, this fines content is between $30-50 \%$ for NWS2-T2 comparing across the samples in Table 2, but appears to be at a fines content of less than $18 \%$ when the density increases. Hence, the results show that the density and fines content effect erosion rate in a coupled manner (i.e. they are not independent effects).

An important realisation based on the observed interdependence of density and fines content is that either parameter on its own is unlikely to be useful for predicting erosion properties of previously-untested sediment. Because of this, it would be ideal if a different single soil parameter, which accounts for the dual effects of density and fines content, could be found to explain trends in erosion rate.

To try and obtain a single soil parameter, it is hypothesised that changes in soil permeability 
due to density and fines content are responsible for the observed changes in erosion properties. This is consistent with permeability being a parameter that reduces by orders of magnitude (in much the same way as the erosion rate) as the density and the fines fraction of a soil is varied.

To investigate if there is a correlation between permeability and erosion rate, a series of Rowe cell tests (with consolidation steps in combination with constant head tests) were carried out to obtain the permeability of NWS1-T1, NWS2-T1 and NWS3-T1 (i.e. the marine sediments with natural particle size composition listed in Table 2) and the artificial sediments. The procedure to obtain permeability for each of the sediments tested is described in detail in Mohr (2015). Fig. 11 shows the measurements of permeability as a function of the voids ratio, e. As shown in Fig. 11, for the artificial sediments, as well as NWS1-T1 and NWS2-T1, the Rowe cell samples exhibited similar densities to that of the erosion test samples (hence interpolation of the permeability measurements was required). For NWS3-T1, the densities in the erosion tests were looser than the tested densities in the Rowe cell test (hence extrapolation of the permeability measurements was required in these cases).

To explore the trend between erosion rate and permeability, the coefficient $M$ is plotted in Fig. 12 as a function of permeability. $M$ has been plotted in this figure as a proxy for erosion rate, since the coefficient $n$ was shown to vary only between $1.5-3$ (see Table 2), whereas changes in $M$ can cover two orders of magnitude. Hence changes in $M$, therefore, control most of the changes in the slope of the erosion rate curve for small shear stresses. The results in Fig. 12 show that there is a reasonably consistent relationship between the erosional parameter $(M)$ and permeability when the permeability is less than $\sim 10^{-5} \mathrm{~m} / \mathrm{s}$. This trend appears to be the same for all of the sediments tested.

To further investigate the relationship between permeability and erosion rate, Fig. 12 also presents erosion data on quartz sediment from Roberts et al. (1998). To plot these additional data, it has been noted that Roberts et al. (1998) presented some of their erosion rate measurements in terms of an empirical formula of the form 


$$
\eta=A_{r} \rho^{m_{r}} \tau^{n_{r}},
$$

where $\rho$ is the density and $A_{r}, n_{r}$ and $m_{r}$ are fitting constants calculated by Roberts et al. (1998) for the different sediment types they tested. Eq. (7) is very similar to Eq. (6) for fine sediments having $\tau_{\text {cr }}^{*} \approx 0$. Hence, it has been assumed that $M \sim A_{r} \rho^{m_{r}}$ in Fig. 12. This simple correction is possible because Roberts et al. (1998) used the same sample length of $150 \mathrm{~mm}$ to that used in the present study.

Roberts et al. (1998) did not report measurements of permeability; however, the KozenyCarman equation can be used to estimate the permeability for their sediment mixtures (and this is likely to be a reasonable approximation for quartz mixtures; Mitchell and Soga 1979). The Kozeny-Carman equation can be written after Chapuis and Aubertin (2003) as

$$
k=C_{\mathrm{K}-\mathrm{C}} \frac{g}{\mu \rho} \frac{1}{S^{2} G_{s}^{2}}\left(\frac{e^{3}}{1+e}\right),
$$

where $C_{\mathrm{K}-\mathrm{C}}$ is the Kozeny-Carman coefficient, $\mu$ is the dynamic viscosity of water (taken to be $1 \times 10^{-3} \mathrm{~Pa}$ s throughout), $S$ is the specific surface and $e$ is the voids ratio. The coefficient $C_{\mathrm{K}-\mathrm{C}}$ was taken as 0.2 , which is usually taken for uniform spheres (Carman 1956). The specific surface $S$ of fine-grained non-plastic soils was approximated based on the formula of Chapuis and Legare (1992). Of course, it should be noted that using the Kozeny-Carman equation can lead to errors in permeability of up to almost one order of magnitude. Additionally, one should note that the data obtained from different erosion studies use different testing techniques and assumptions, suggesting that any comparison should be conducted with caution.

The interpretation of Roberts et al. (1998)'s erosion coefficient and the estimated permeability from Eq. (8) leads to the data presented in Fig. 12. With respect to Roberts et al. (1998) data in Fig. 12 it can be seen that, despite the assumptions made in reinterpreting the data, there is a remarkably similar trend to that observed for the erosion behaviour of the marine NWS sediments and artificial sediments tested in this study. 
As a final comparison, $M$ has also been plotted against permeability for a range of particle sizes based on Yalin's bedload transport expression and the Kozeny-Carman equation. More specifically to obtain the parameter $M$, the bedload transport expression given in Eq. (3a) has been converted to an erosion rate comparable to the underlying erosion tests of this study. Therefore, the dimensionless bedload transport rate was dimensionalised using Eq. (4) and then converted to an erosion rate using Eq. (5) with $L=150 \mathrm{~mm}$. Finally, the calculated erosion rates were then fitted to the empirical equation in (6) to obtain $M$. Secondly, the permeability was calculated using the Kozeny-Carman equation assuming a single-sized sediment at a voids ratio of 0.4 (see Fig. 12, bold black line). Two additional curves are also shown representing a looser single-sized sediment $(e=0.8)$ and a more graded material (assuming a doubled specific surface compared to a single-sized sediment).

It can be seen in Fig. 12 that the resulting curves (each plotted for a different density and particle size distribution) are in very good agreement with the measured data when permeability $>10^{-5} \mathrm{~m} / \mathrm{s}$. Specifically, assuming a sample length of $150 \mathrm{~mm}$, the results suggest that for any material obeying the bedload transport relationship of Yalin (1963) $M$ is expected to vary approximately between $10^{-3}$ and $10^{-5} \mathrm{~m} /\left(\mathrm{Pa}^{\mathrm{n}} \mathrm{s}\right)$, whereas marine sediments can have $M$-values far below $10^{-5} \mathrm{~m} /\left(\mathrm{Pa}^{\mathrm{n}} \mathrm{s}\right)$ if their permeability is less than $\sim 10^{-} 5 \mathrm{~m} / \mathrm{s}$.

\subsection{A theoretical argument for the correlation between permeability and erosion rate}

Based on dimensional analysis, Mohr (2015) proposed a dimensionless expression including permeability, shear stress and erosion rate which can be expressed close to threshold as

$$
\frac{\tau}{\left(\rho_{s}-\rho\right) g d}=\mathrm{F}^{\prime}(\mathrm{Re}) \times\left(1+7.7 \frac{\eta}{k}\right)
$$

where $k$ is the permeability of the sediments. The term $F^{\prime}(\mathrm{Re})$ in Eq. (9) is an empirical function depending on the grain Reynolds number. In Mohr (2015), this value is taken to be equal to the critical Shields parameter based on the empirical Shields curve (i.e. $\mathrm{F}^{\prime}(\mathrm{Re}) \sim \theta_{\mathrm{cr}}^{*}$ ), which is likely to be a good assumption when the shear stress is not much larger than the critical shear stress 
predicted by the Shields curve. Rearranging Eq. (9) with $\mathrm{F}^{\prime}(\mathrm{Re})=\theta_{\mathrm{cr}}^{*}$ leads to

$$
\eta=M_{s e}\left(\tau-\tau_{\mathrm{cr}}^{*}\right)
$$

with

$$
M_{s e}=\frac{1}{7.7} \frac{k}{\tau_{\mathrm{cr}}^{*}} .
$$

In Eq. (10), $\tau_{\mathrm{cr}}^{*}=\theta_{\mathrm{cr}}^{*}\left(\rho_{s}-\rho\right) g d$ is the critical Shields parameter at zero erosion rate (given by the empirical Shields curve) and is, therefore, smaller than the shear stress values estimated throughout this paper (which correspond to an erosion rate of $10^{-7} \mathrm{~m} / \mathrm{s}$ ). It is also important to note, as mentioned in Mohr (2015), that the relationship given by Eq. (10) is only expected to be valid when the sediment is close to threshold conditions experiencing surface erosion (see Torfs 1995 and Winterwerp and van Kesteren 2004 for further discussion on surface erosion). If the shear stress and erosion rate are too high, material may be removed/sheared from the sample which is often described as mass erosion (see Winterwerp and van Kesteren 2004).

To compare Eq. (10) with the present experimental data, Fig. 13 shows the result from Eq. (10) together with the erosion rate measurements for NWS3-T1. Also shown on Fig. 13 are (i) a dashed vertical line indicating the threshold shear stress corresponding to the Shields curve, (ii) a red horizontal line indicating an erosion rate of $10^{-7} \mathrm{~m} / \mathrm{s}$, and (iii) a gray shaded area indicating when clumps of sediment were first observed to be removed from the sample, indicating initiation of mass erosion. To demonstrate the transition to mass erosion, Fig. 14 presents photographs of the sample before and after a constant shear stress test with $\sim 1.3$ and $\sim 2.3$ times the threshold shear stress of $\sim 0.74 \mathrm{~Pa}$. At $\sim 1.3$ times the threshold shear stress, no clumps had been dislodged, and the sample surface is evidently smooth. In comparison, at $\sim 2.3$ times the threshold shear stress clumps had been dislodged, leading to a rougher sample surface. Collectively, the photographs in Fig. 14(b) and 14(c) show clearly the patterns that are also described by Winterwerp and van Kesteren (2004) for surface and mass erosion, respectively. For convenience, the erosion measurements 
corresponding to the photographs in Fig. 14(c) are labelled in Fig. 13(c) agreeing well with the indicated regions of surface and mass erosion.

As shown in Fig. 13, the experimental data shows very good agreement with Eq. (10) prior to the initiation of mass erosion across all of the densities for which samples of NWS3-T1 were tested. To compare with additional samples tested (NWS1-T1, NWS2-T1), Fig. 15 shows the prediction for $M_{s e}$ based on Eq. (10) together with the gradient from a linear regression using erosion measurements just above $\tau_{\mathrm{cr}}^{*}$ before mass erosion was observed. It should be noted that tests NWS1-T1 and NWS2-T1 (besides NWS2-T1 with a density $1914 \mathrm{~kg} / \mathrm{m}^{3}$ ) were observed to always erode particle by particle (e.g. no mass erosion occurred). Good agreement can be observed in Fig. 15 between the predictions and the measurements exhibiting a linear correlation with permeability.

Further research should be undertaken to understand the influence of permeability in the higher shear stress region or if other parameters, such as the undrained shear strength, are more suitable when mass erosion is observed (as suggested, for example, by Winterwerp and van Kesteren 2004).

\section{CONCLUSION}

For marine sediments with an increased fraction of fines (sufficient that their threshold shear stress exceeds that predicted from the empirical Shields curve) the erosion behaviour deviates from the traditional bedload transport equations. In this regime, both density and fines content affect the

erosion rate. Specifically, the erosion rate for a given shear stress decreases with increasing density and fines content. Furthermore, the sensitivity to density increases with an increase in fines content.

A unique relationship between permeability and erosion rate (defined in terms of the fitted parameter $M$ ) has been observed for marine sediments obtained from the NWS of Australia. A very similar trend has also been observed by reinterpreting the data in Roberts et al. (1998) for quartz sediment, suggesting that permeability may be a useful metric to predict erosion rate behaviour of untested marine sediments.

The erosion rate close to threshold conditions (in which the mode of erosion is surface erosion) appears to be consistent with the dimensionless expression presented by Mohr (2015). Further 
experiments are required to investigate the suitability of this model including the underlying theory, and to consider which parameters control the erosion behaviour of marine sediments at larger shear stresses when mass erosion is observed.

\section{ACKNOWLEDGMENTS}

This research forms part of the activities of the Centre of Offshore Foundation Systems (COFS), supported as a node of the Australian Research Council's Centre of Excellence for Geotechnical Science and Engineering (CGSE), and through the Fugro Chair in Geotechnics, the Lloyd's Register Foundation Chair and Centre of Excellence in Offshore Foundations. The first author acknowledges his Research Studentship support from The University of Western Australia. The first and second author acknowledge the support of the Lloyd's Register Foundation. The Foundation helps to protect life and property by supporting engineering-related education, public engagement and the application of research. This research is supported through ARC Discovery Grants Program: DP130104535.

\section{REFERENCES}

Buffington, J. M. and Montgomery, D. R. (1997). "A systematic analysis of eight decades of incipient motion studies, with special reference to gravel-bedded rivers." Water Resources Research, 33(8), 1993-2029.

Carman, P. C. (1956). Flow of gases through porous media. Butterworths Scientific Publications, London.

Chapuis, R. P. and Aubertin, M. (2003). Predicting the coefficient of permeability of soils using the Kozeny-Carman equation. Technical Report (EPM-RT-200303), École Polytechnique de Montréal.

Chapuis, R. P. and Legare, P.-P. (1992). "A simple method for determining the surface area of fine aggregates and fillers in bituminous mixtures." Effects of aggregates and mineral fillers on asphalt mixture performance, 1147, 177-186.

Christoffersen, J. B. and Jonsson, I. (1985). "Bed friction and dissipation in a combined current and wave motion." Ocean Engineering, 12(5), 387-423. 
Gilbert, G. K. and Murphy, E. C. (1914). The transportation of debris by running water. US Government Printing Office, Reston.

Jacobs, W., Le Hir, P., van Kesteren, W., and Cann, P. (2011). "Erosion threshold of sand-mud mixtures." Continental Shelf Research, 31, 14-25.

Kramer, H. (1935). "Sand mixtures and sand movement in fluvial models." Transactions of the American Society of Civil Engineers, 100, 798-878.

Leckie, S. H. F., Draper, S., White, D. J., Cheng, L., and Fogliani, A. (2015). "Lifelong embedment and spanning of a pipeline on a mobile seabed." Coastal Engineering, 95, 130-146.

Lonsdale, P. and Southard, J. B. (1974). "Experimental erosion of north pacific red clay." Marine Geology, 17(1), M51-M60.

McCave, I. N. (1984). “Erosion, transport and deposition of fine-grained marine sediments.” Geological Society, 15, 35-69.

Miller, M. C., McCave, I. N., and Komar, P. D. (1977). "Threshold of sediment motion under unidirectional currents.” Sedimentology, 24(4), 507-527.

Mitchell, J. K. and Soga, K. (1979). Fundamentals of soil behavior. Wiley, New York.

Mitchener, H., Torfs, H., and Whitehouse, R. J. S. (1996). “Erosion of mud/sand mixtures.” Coastal Engineering, 29, 1-25 (Errata, 1997, 30, 319).

Mohr, H. (2015). "Erosion and scour behaviour of marine sediments." Ph.D. thesis, University of Western Australia, Australia.

Mohr, H., Draper, S., Cheng, L., White, D. J., An, H., and Zhang, Q. (2016a). “The hydrodynamics of a recirculating (O-tube) flume." Proc. 8th International Conference on Scour and Erosion, 999-1010.

Mohr, H., Draper, S., and White, D. J. (2013). "Free field sediment mobility on Australia's North West Shelf." Proc. 32nd International Conference on Ocean, Offshore and Arctic Engineering, V04BT04A051, 11 pages.

Mohr, H., Draper, S., White, D. J., and Cheng, L. (2016b). "Predicting the rate of scour beneath subsea pipelines in marine sediments under steady flow conditions." Coastal Engineering, 110, 
$111-126$.

Nairn, B. J. (1998). “Incipient transport of silt-sized sediments.” Ph.D. thesis, California Institute of Technology, United States.

Nikuradse, J. (1933). Laws of flow in rough pipes. National Advisory Committee for Aeronautics, Washington D.C.

Panagiotopoulos, I., Voulgaris, G., and Collins, M. B. (1997). "The influence of clay on the threshold of movement of fine sandy beds." Coastal Engineering, 32, 19-43.

Roberts, J. D., Jepsen, R., Gotthard, D., and Lick, W. (1998). "Effects of particle size and bulk density on erosion of quartz particles." Journal of Hydraulic Engineering, 124(12), 1261-1267.

Shields, A. (1936). "Anwendung der aehnlichkeitsmechanik und der turbulenzforschung auf die geschiebebewegung." Ph.D. thesis, Preußische Versuchsanstalt für Wasserbau und Schiffbau, Germany.

Smith, D. A. and Cheung, K. F. (2004). "Initiation of motion of calcareous sand." Journal of Hydraulic Engineering, 130(5), 467-472.

Soulsby, R. L. (1997). Dynamics of marine sands: A manual for practical applications. Thomas Telford, London.

Soulsby, R. L. and Whitehouse, R. J. S. (1997). "Threshold of sediment motion in coastal environments." Proc. 13th Australasian Coastal and Ocean Engineering Conference and 6th Australasian Port and Harbour Conference, 1, 145.

Southard, J. B., Young, R. A., and Hollister, C. D. (1971). "Experimental erosion of calcareous ooze." Geophysical Research, 76(24).

Torfs, H. (1995). "Erosion of mud/sand mixtures.” Ph.D. thesis, Katholieke Universiteit Leuven, Belgium.

Whitehouse, R. J. S., Soulsby, R., Roberts, W., and Mitchener, H. (2000). Dynamics of estuarine muds. Thomas Telford Publishing, London.

Wiberg, P. L. and Smith, J. D. (1989). "Model for calculating bed load transport of sediment." Journal of Hydraulic Engineering, 115(1), 101-123. 
Wilson, K. C. (1966). "Bed-load transport at high shear stress." Journal of the Hydraulics Division, 92(11), 49-59.

Winterwerp, J. C. and van Kesteren, W. G. M. (2004). Introduction to the physics of cohesive sediment in the marine environment. Elsevier, Amsterdam.

Yalin, M. S. (1963). "An expression for bed-load transportation." Journal of the Hydraulics Division, 89(3), 221-250.

Ye, Z. (2012). "Erosion threshold and erosion rate of seabed sediments." Ph.D. thesis, University of Western Australia, Australia. 


\section{NOTATION}

$$
\begin{aligned}
& A_{r}=\text { Fitting parameter from Roberts et al. (1998) } \\
& C_{\mathrm{K}-\mathrm{C}}=\text { Kozeny-Carman coefficient } \\
& \text { Clay }=\text { Percentage of particles }<2 \mu \mathrm{m} \\
& C_{u}=\text { Uniformity index } \\
& d=\text { Particle diameter } \\
& d_{50}=\text { Median grain size } \\
& D_{*}=\text { Dimensionless grain size } \\
& e=\text { Voids ratio } \\
& \mathrm{F}^{\prime}=\text { Empirical function depending on the grain Reynolds number } \\
& \text { Fines }=\text { Percentage of particles }<75 \mu \mathrm{m} \text { (for present study) } \\
& g=\text { Gravity } \\
& G_{s}=\text { Specific gravity } \\
& k=\text { Permeability } \\
& k_{v}=\text { Permeability in vertical flow direction } \\
& L=\text { Sample length } \\
& m_{r}=\text { Fitting parameter from Roberts et al. (1998) } \\
& M=\text { Fitting parameter } \\
& M_{s e}=\text { Fitting parameter } \\
& m_{r}=\text { Fitting parameter from Roberts et al. (1998) } \\
& n=\text { Fitting parameter } \\
& q_{b}=\text { Bedload transport rate } \\
& \operatorname{Re}=\text { Reynolds number } \\
& S=\text { Specific surface } \\
& \delta^{\prime}=\text { Calibration factor } \\
& \epsilon=\text { Porosity } \\
& \eta=\text { Apparent erosion rate } \\
& \theta=\text { Dimensionless shear stress }
\end{aligned}
$$




$$
\begin{aligned}
\theta_{\mathrm{cr}} & =\text { Dimensionless threshold shear stress } \\
\theta_{\mathrm{cr}}^{*} & =\text { Critical Shields parameter } \\
\mu & =\text { Dynamic fluid viscosity } \\
\nu & =\text { Kinematic fluid viscosity } \\
\rho & =\text { Fluid density (or water density) } \\
\rho_{\mathrm{bulk}} & =\text { Bulk density } \\
\rho_{s} & =\text { Density of sediment grain } \\
\tau & =\text { Shear stress } \\
\tau_{\mathrm{cr}} & =\text { Threshold shear stress } \\
\tau_{\mathrm{cr}}^{*} & =\text { Threshold shear stress based on the Shields curve } \\
\Phi & =\text { Dimensionless bed load transport rate }
\end{aligned}
$$




\begin{tabular}{cccccc}
\hline Soil name & $\begin{array}{c}d_{50} \\
(\mathrm{~mm})\end{array}$ & $\begin{array}{c}G_{s} \\
(-)\end{array}$ & $\begin{array}{c}C_{u} \\
(-)\end{array}$ & $\begin{array}{c}\text { Fines }^{1} \\
(\%)\end{array}$ & $\begin{array}{c}\text { Clay }^{2} \\
(\%)\end{array}$ \\
\hline NWS1 & 0.31 & 2.78 & 3 & 7.5 & 0.9 \\
NWS2 & 0.18 & 2.74 & 8 & 17.7 & 2.7 \\
NWS3 & 0.12 & 2.76 & 112 & 38.9 & 8.2 \\
SS1 & 0.54 & 2.75 & 1 & 0 & 0 \\
SS2 & 0.19 & 2.67 & 2 & 0 & 0 \\
\hline $1<75 \mu \mathrm{m}$ & & & & & \\
$2<2 \mu \mathrm{m}$ & & & & &
\end{tabular}

TABLE 1: Soil properties of two silica sediments and three North West Shelf sediments. 


\begin{tabular}{ccccc}
\hline Soil name & $\begin{array}{c}\rho_{\text {bulk }} \\
\left(\mathrm{kg} / \mathrm{m}^{3}\right)\end{array}$ & $\begin{array}{c}\tau_{\text {cr }} \\
(\mathrm{Pa})\end{array}$ & $\begin{array}{c}M \\
\left(\mathrm{~m} /\left(\mathrm{Pa}^{\mathrm{n}} \mathrm{s}\right)\right)\end{array}$ & $\begin{array}{c}n \\
(-)\end{array}$ \\
\hline \multirow{3}{*}{ NWS1-T1 } & 1890 & 0.214 & $7.4 \mathrm{E}-05$ & 1.6 \\
& 1928 & 0.308 & $5.1 \mathrm{E}-05$ & 2.3 \\
& 1971 & 0.42 & $4.5 \mathrm{E}-05$ & 3.0 \\
\hline \multirow{3}{*}{ NWS2-T1 } & 1830 & 0.271 & $8.0 \mathrm{E}-05$ & 1.9 \\
& 1852 & 0.315 & $1.5 \mathrm{E}-05$ & 2.5 \\
& 1914 & 0.595 & $3.1 \mathrm{E}-07$ & 2.5 \\
\hline & 1624 & 0.258 & $4.5 \mathrm{E}-06$ & 1.5 \\
NWS3-T1 & 1691 & 0.609 & $1.1 \mathrm{E}-06$ & 2.7 \\
& 1715 & 0.738 & $3.0 \mathrm{E}-07$ & 2.8 \\
& 1757 & 0.957 & $1.6 \mathrm{E}-07$ & 3.0 \\
\hline
\end{tabular}

TABLE 2: Testing schedule for marine sediments from Table 1 with varying density (type 1). 


\begin{tabular}{ccccccc}
\hline Soil name & $\begin{array}{c}\text { Fines }^{1} \\
(\%)\end{array}$ & $\begin{array}{c}d_{50} \\
(\mathrm{~mm})\end{array}$ & $\begin{array}{c}\rho_{\text {bulk }} \\
\left(\mathrm{kg} / \mathrm{m}^{3}\right)\end{array}$ & $\begin{array}{c}\tau_{\text {cr }} \\
(\mathrm{Pa})\end{array}$ & $\begin{array}{c}M \\
\left(\mathrm{~m} /\left(\mathrm{Pa}^{\mathrm{n}} \mathrm{s}\right)\right)\end{array}$ & $\begin{array}{c}n \\
(-)\end{array}$ \\
\hline & 0 & 0.22 & 1830 & 0.198 & $9.7 \mathrm{E}-5$ & 1.8 \\
NWS2-T2 & 17.7 & 0.18 & 1799 & 0.271 & $8.0 \mathrm{E}-5$ & 1.9 \\
& 30 & 0.14 & 1852 & 0.262 & $9.2 \mathrm{E}-5$ & 2.0 \\
& 50 & 0.075 & 1779 & 0.289 & $4.8 \mathrm{E}-5$ & 2.4 \\
& 100 & 0.026 & 1734 & 0.786 & $3.2 \mathrm{E}-6$ & 4.9 \\
\hline \multirow{3}{*}{ NWS3-T2 } & 0 & 0.21 & 1824 & 0.198 & $1.0 \mathrm{E}-4$ & 1.8 \\
& 100 & 0.12 & 1691 & 0.609 & $1.1 \mathrm{E}-6$ & 2.8 \\
& 0.013 & 1739 & 0.844 & $3.4 \mathrm{E}-7$ & 2.0 \\
\hline
\end{tabular}

$$
1<75 \mu \mathrm{m}
$$

TABLE 3: Testing schedule for marine sediments from Table 1 with varying fines content (type 2). 


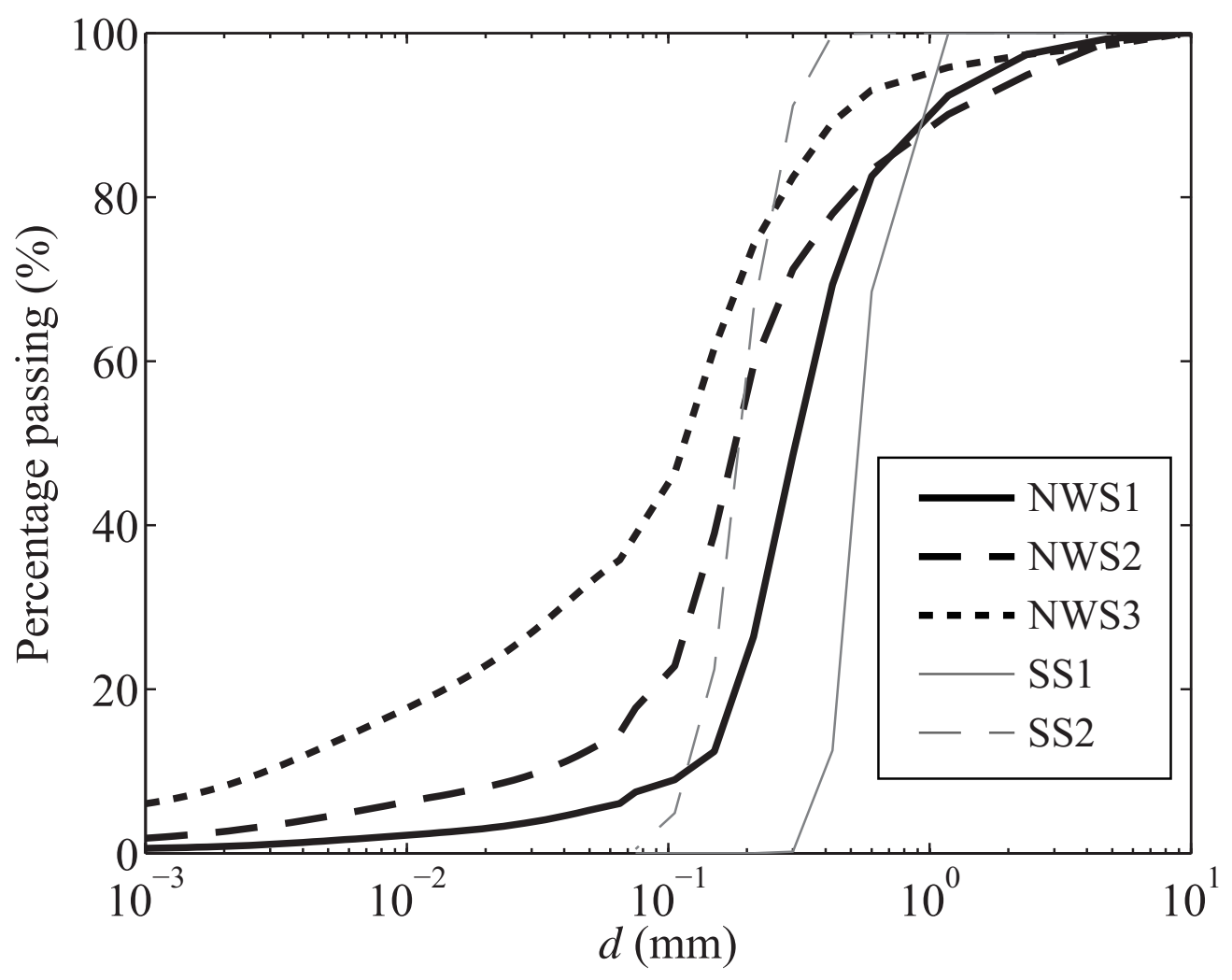

FIG. 1: Particle size distribution for tested sediments. 

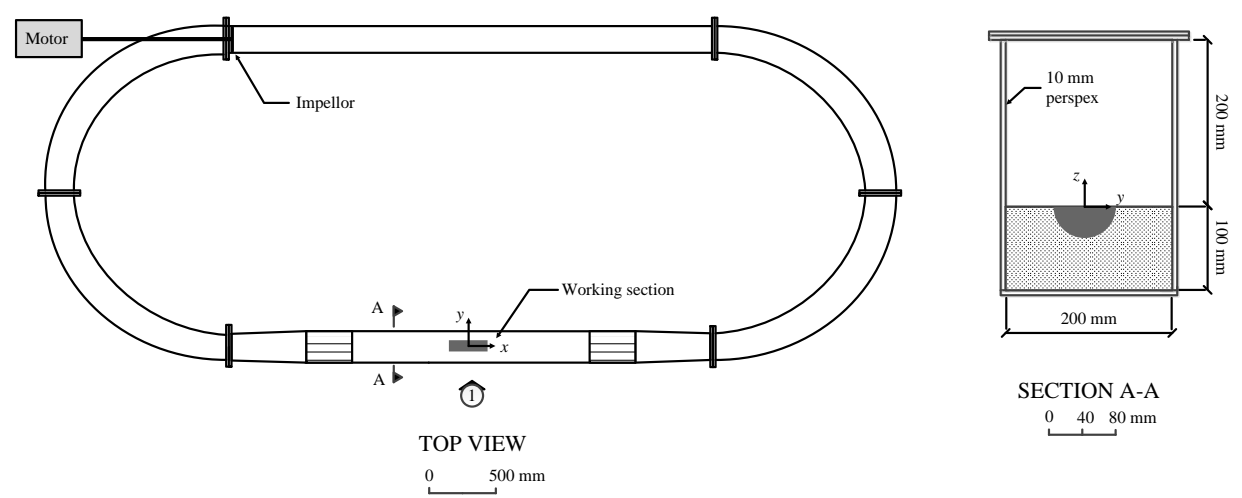

\section{SECTION A-A} $0 \quad 40 \quad 80 \mathrm{~mm}$

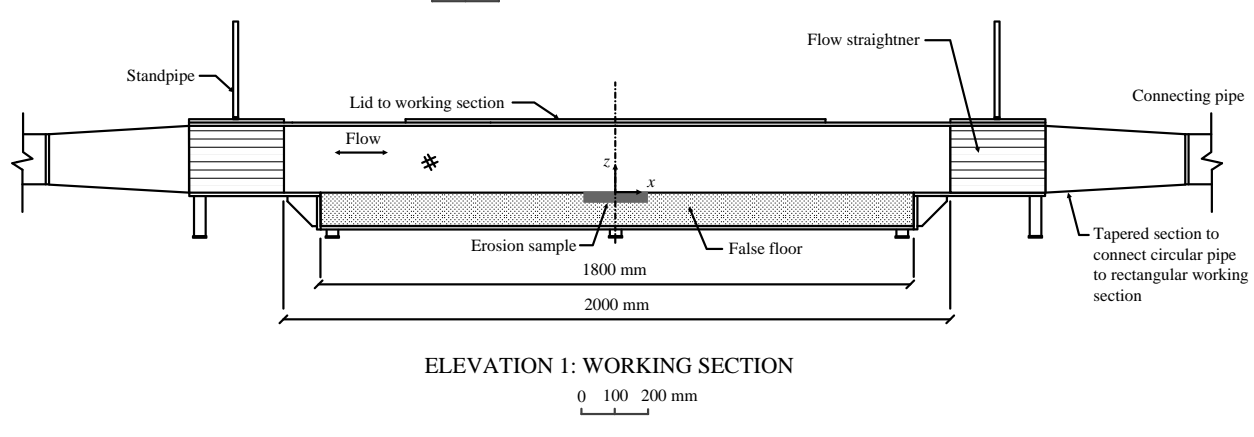

FIG. 2: Experimental test setup - The Mini O-tube. 


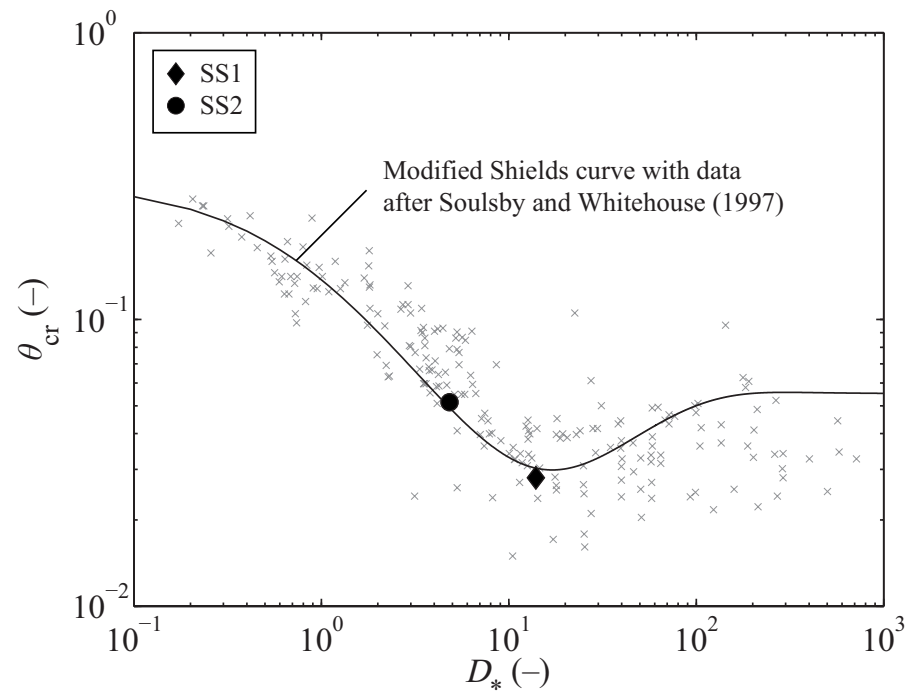

(a) Shields curve.

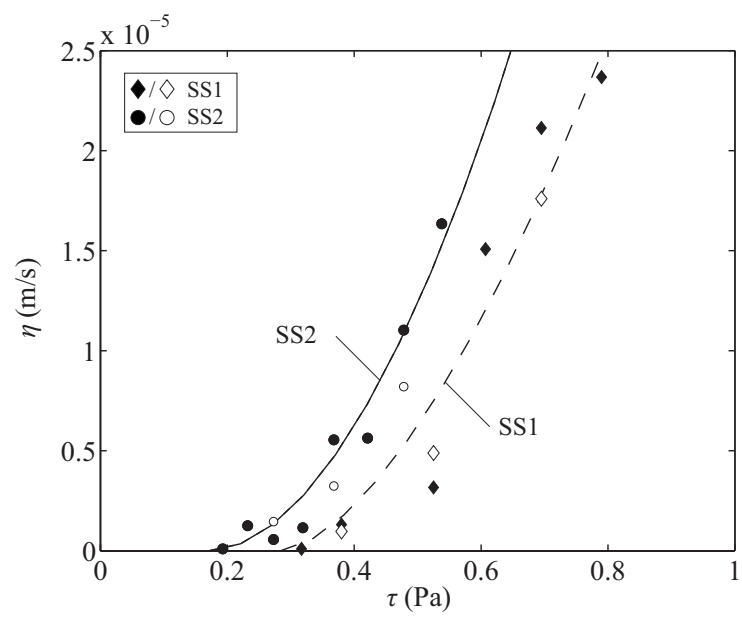

(b) Erosion rates.

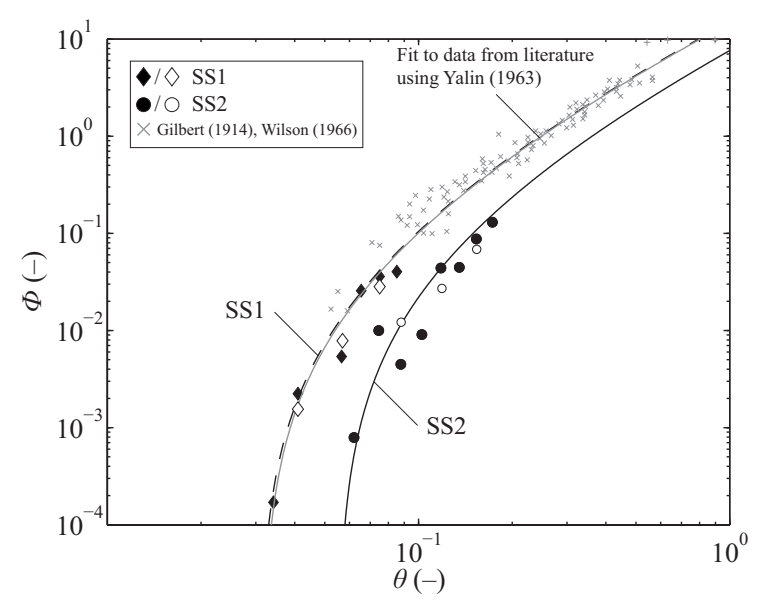

(c) Transport rates.

FIG. 3: Erosion measurements for silica sediments (see Table 1). The Shields values in (a) are shown with the Shields data and curve after Soulsby and Whitehouse (1997); the erosion rates in (b) are shown with the fitted lines from Eq. (6) and the transport rates in (c) with Yalin's fit (Eq. (3a)) assuming $\theta_{\text {cr }}$ from the Shields curve. 


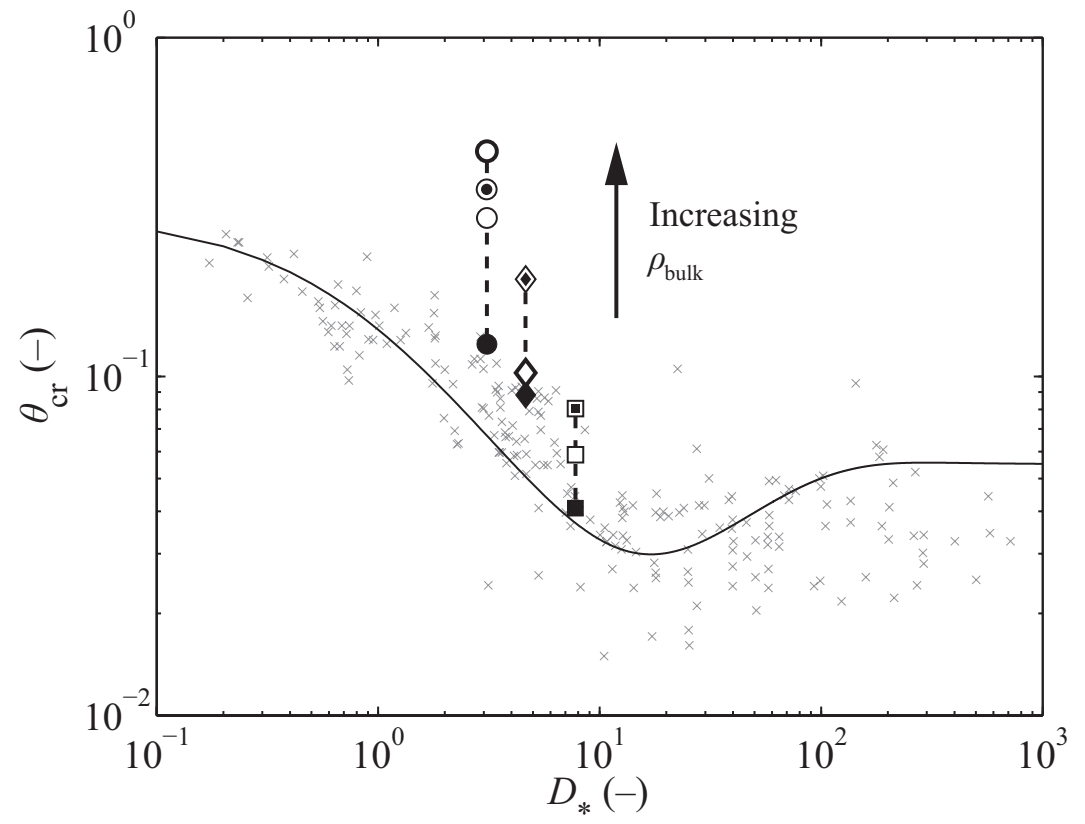

FIG. 4: Dimensionless threshold shear stress for sediments with varying density shown in Table 2 with squared symbols for NWS1-T1, diamond-shaped symbols for NWS2-T1 and circular symbols for NWS3-T1. The solid line indicates the Shields curve shown as the empirical fit from Soulsby and Whitehouse (1997) and the crosses are data compiled by Soulsby and Whitehouse (1997). 


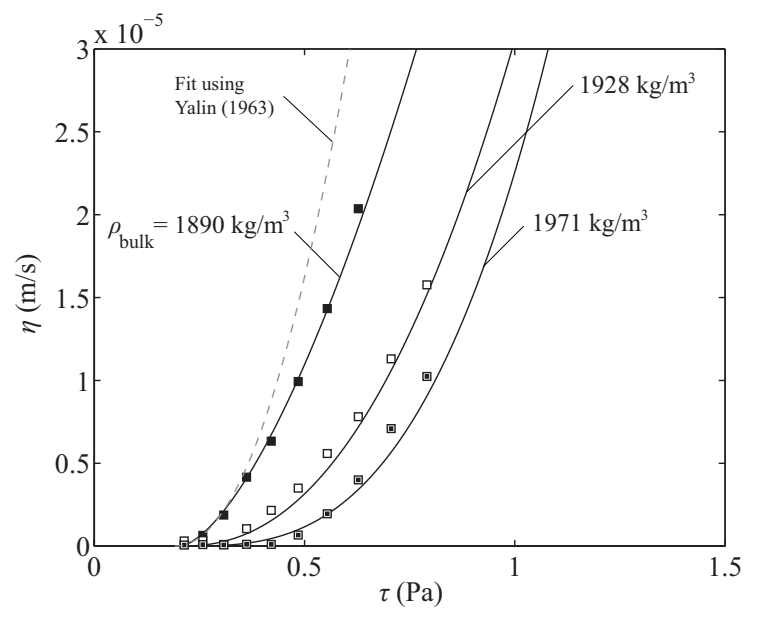

(a) NWS1-T1

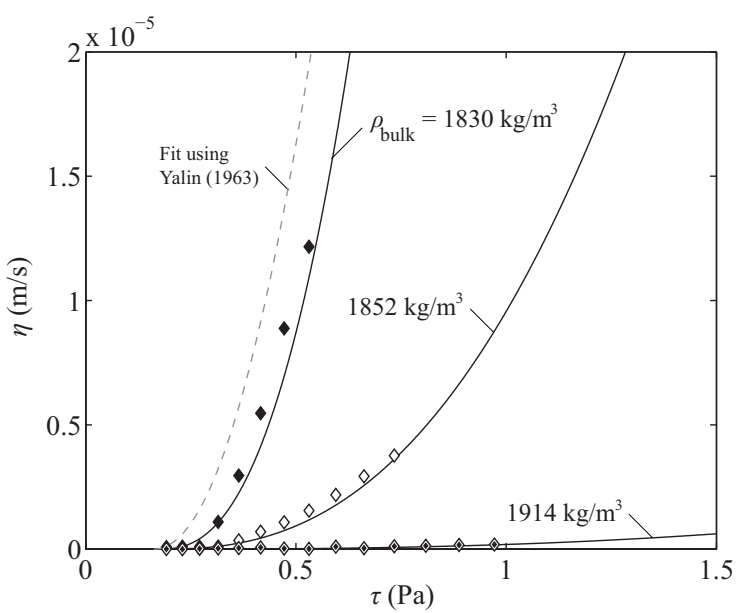

(b) NWS2-T1

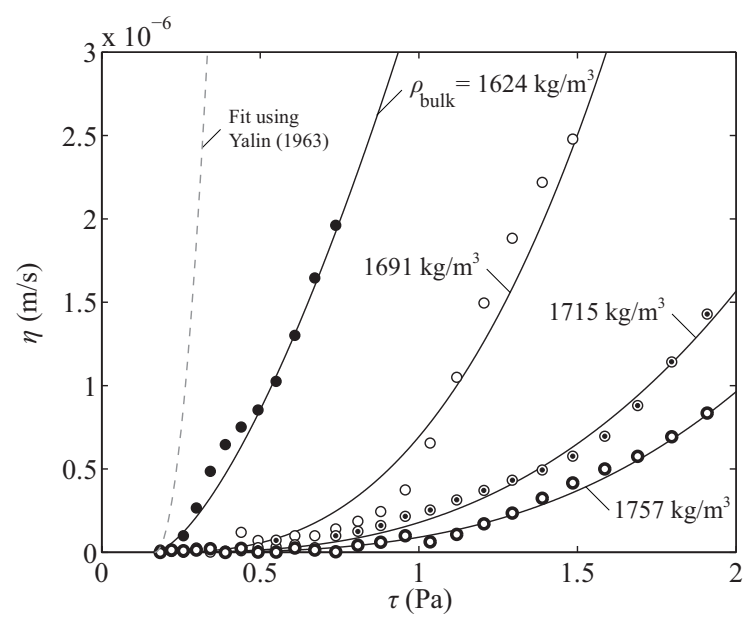

(c) NWS3-T1

FIG. 5: Erosion rate measurements for samples in Table 2. Black lines indicate the best fit of Equation (6) and the grey line indicates the transformed erosion rate from Equation (3a). 


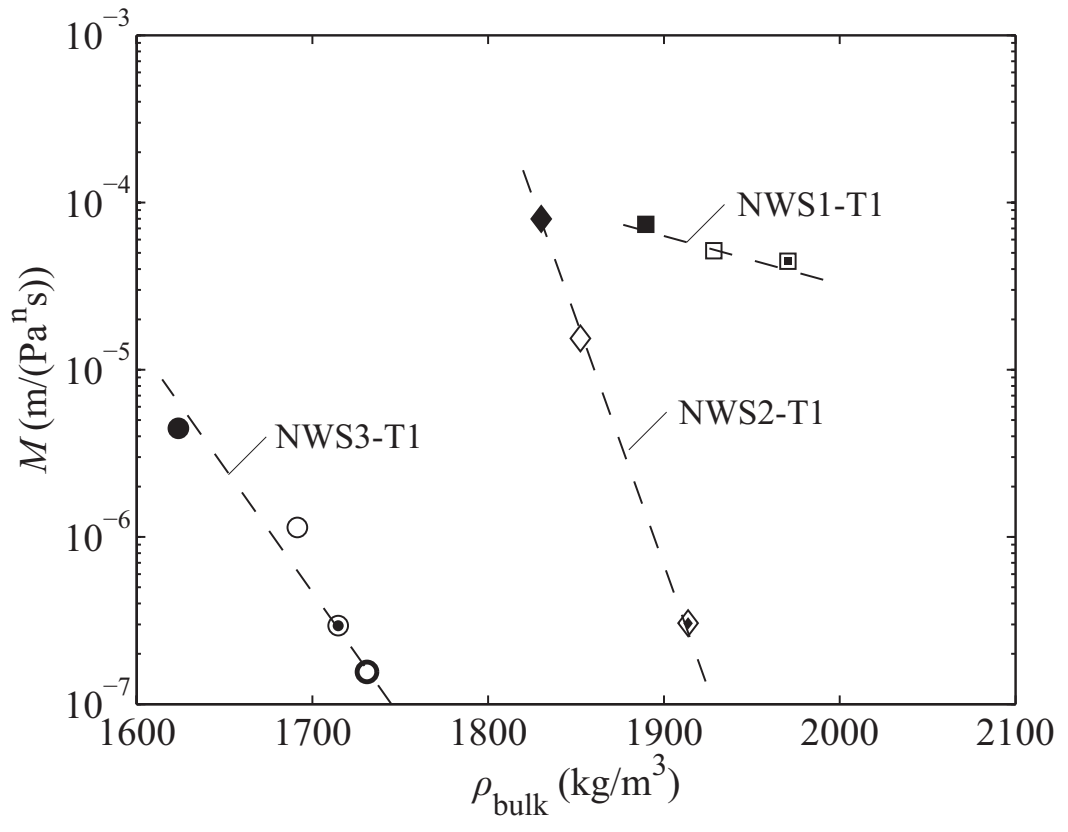

FIG. 6: Fitted parameter $M$ as a function of bulk density with square symbols for NWS1-T1, diamond symbols for NWS2-T1 and circular symbols for NWS3-T1. Dashed lines show trend. 


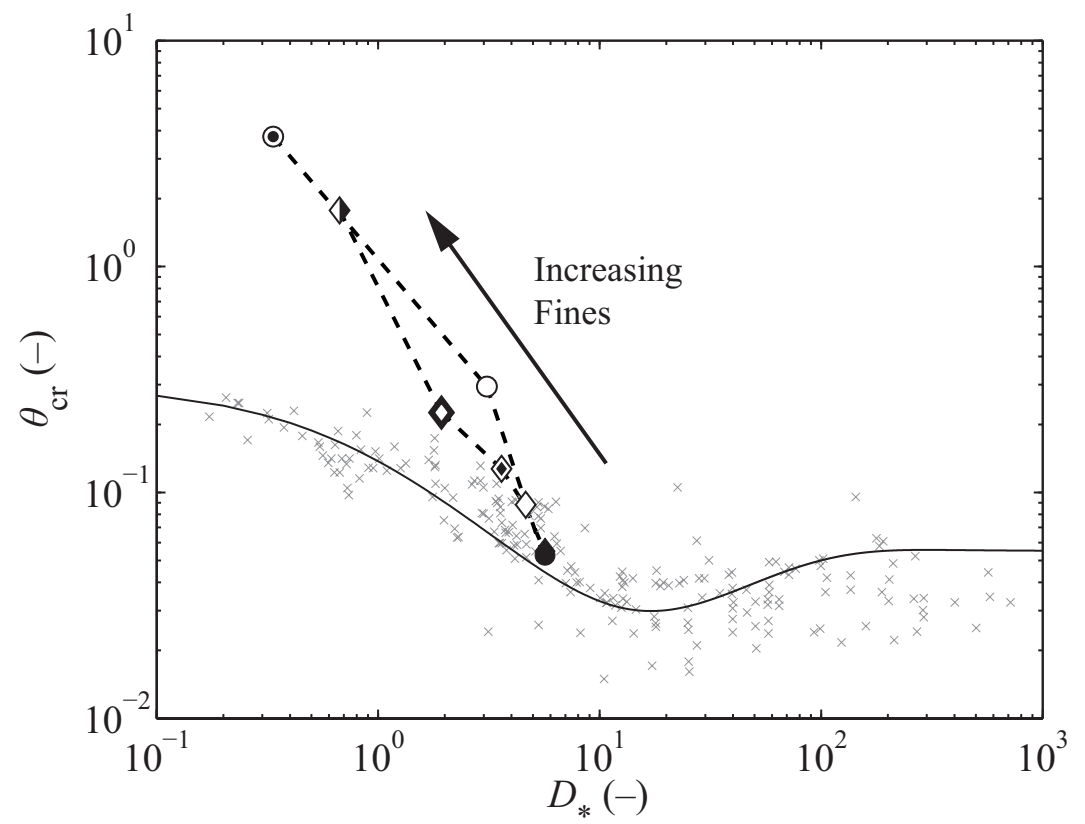

FIG. 7: Dimensionless threshold shear stress for sediments with increasing fines content listed in Table 3 with diamond-shaped symbols for NWS2-T2 and circular symbols for NWS3-T2. The solid line indicates the Shields curve shown as the empirical fit from Soulsby and Whitehouse (1997) and the crosses are data compiled by Soulsby and Whitehouse (1997). 


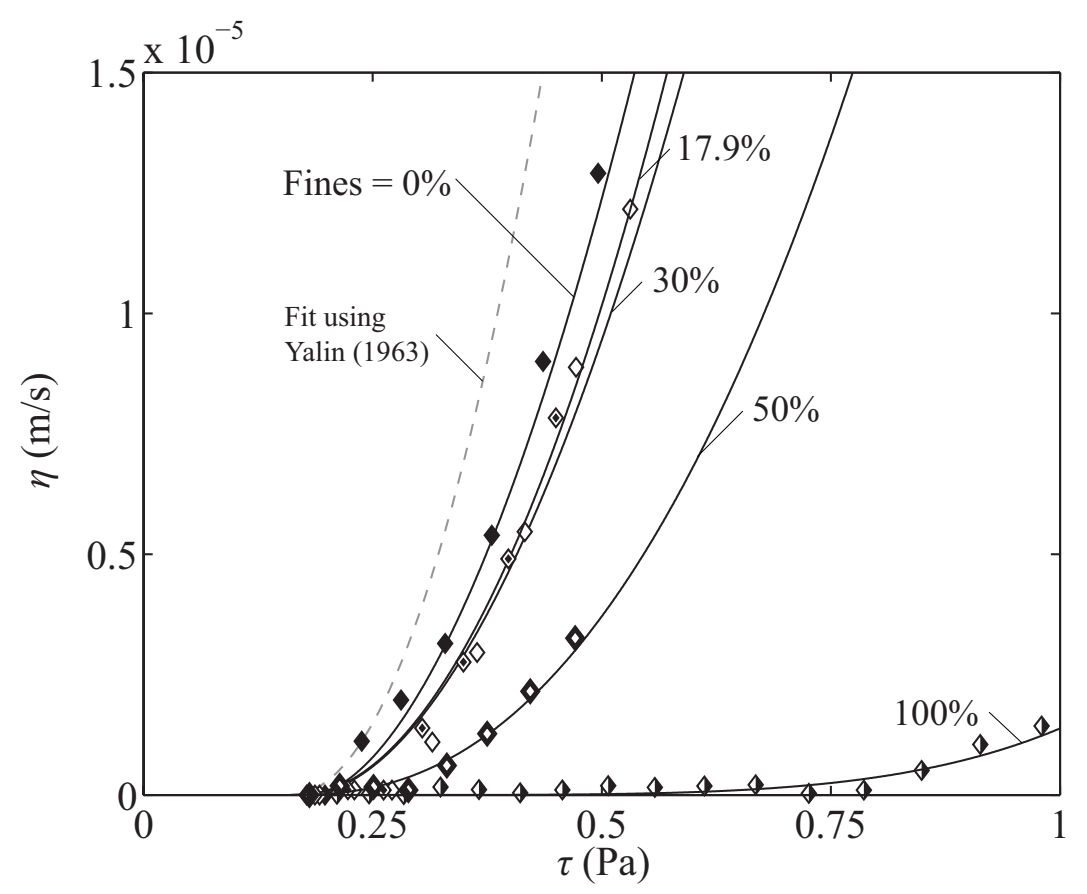

(a) NWS2-T2

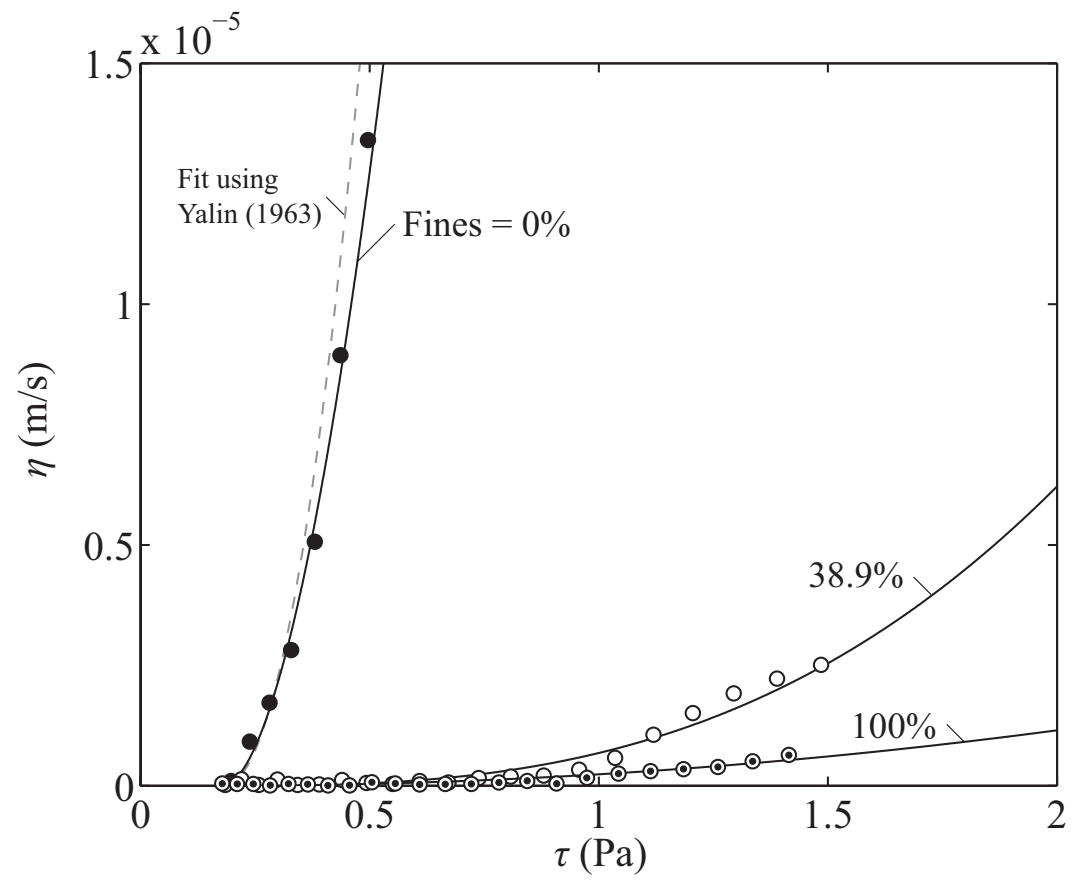

(b) NWS3-T2

FIG. 8: Erosion rate measurements for sediments with different fines content in Table 3; best fit according to Equation (6) shown as lines. 


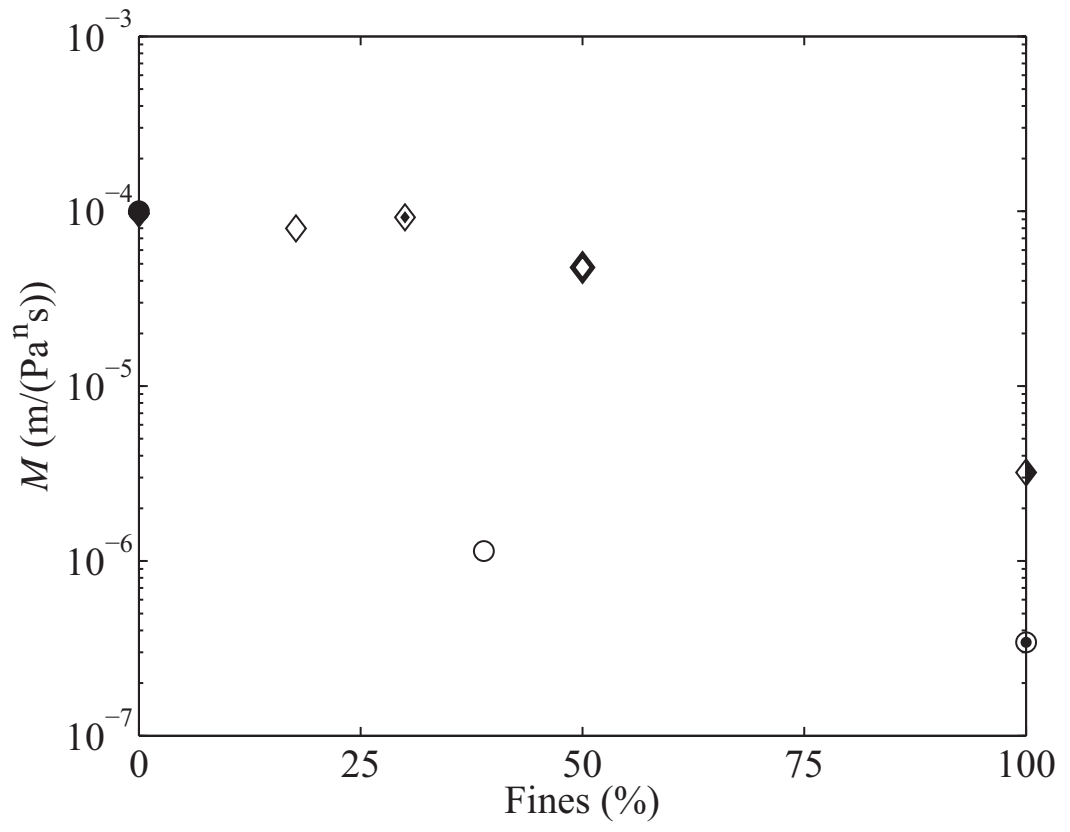

FIG. 9: Fitted parameter $M$ as a function of fines content for sediments in Table 3 with diamond symbols for NWS2-T2 and circle symbols for NWS3-T2. 


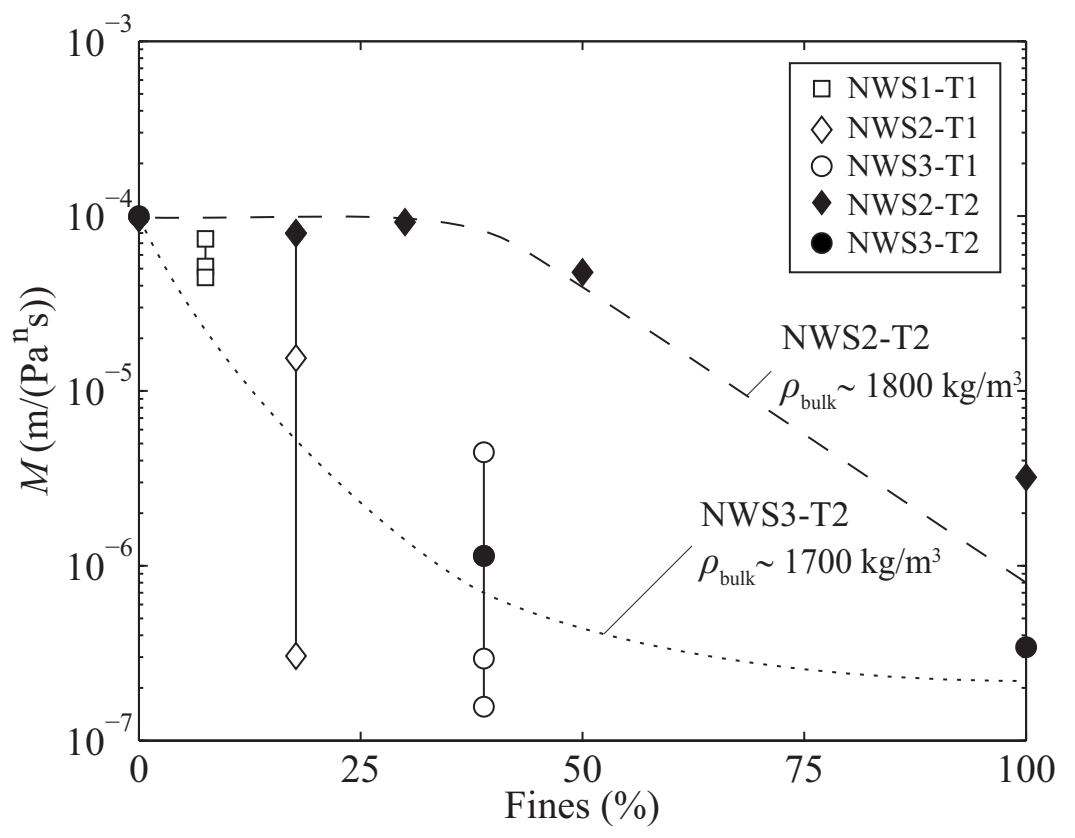

FIG. 10: Fitted parameter $M$ as a function of fines content for sediments listed in Table 3. The symbols with error bars indicate changes due to densities variation with constant fines content (see Table 2). The dashed line gives a rough estimate for a constant density for NWS2-T2 ( $\left.1800 \mathrm{~kg} / \mathrm{m}^{3}\right)$ and the dotted lines for NWS3-T2 $\left(\sim 1700 \mathrm{~kg} / \mathrm{m}^{3}\right)$. 


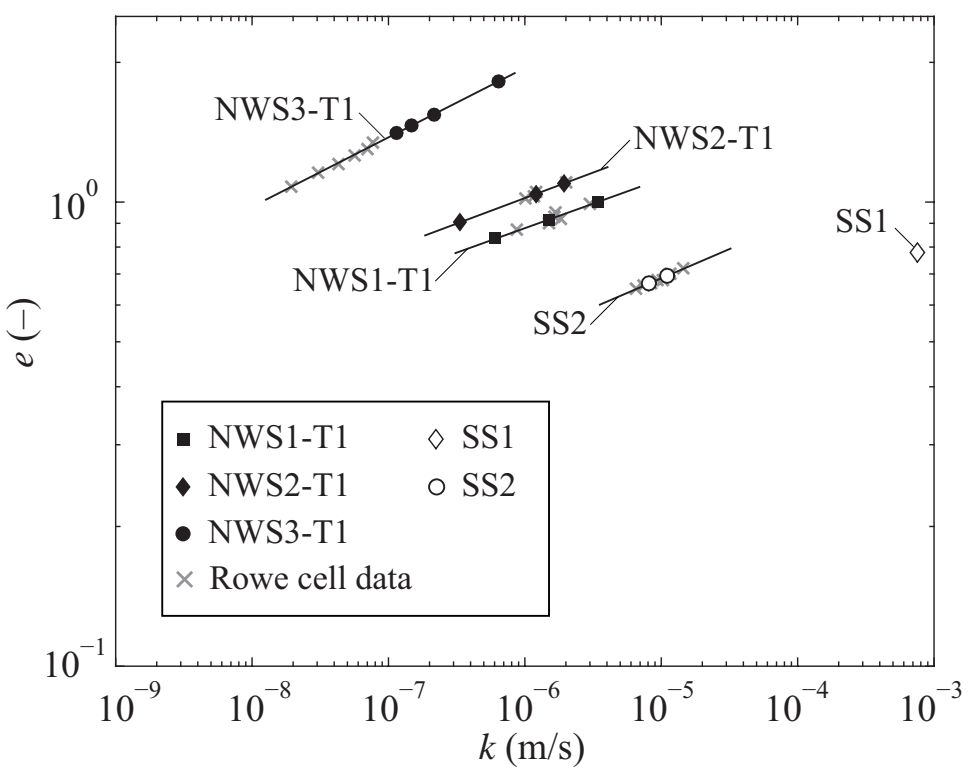

FIG. 11: Permeability against voids ratio for each sediment approximated by means of bulk density measurements from erosion tests. 


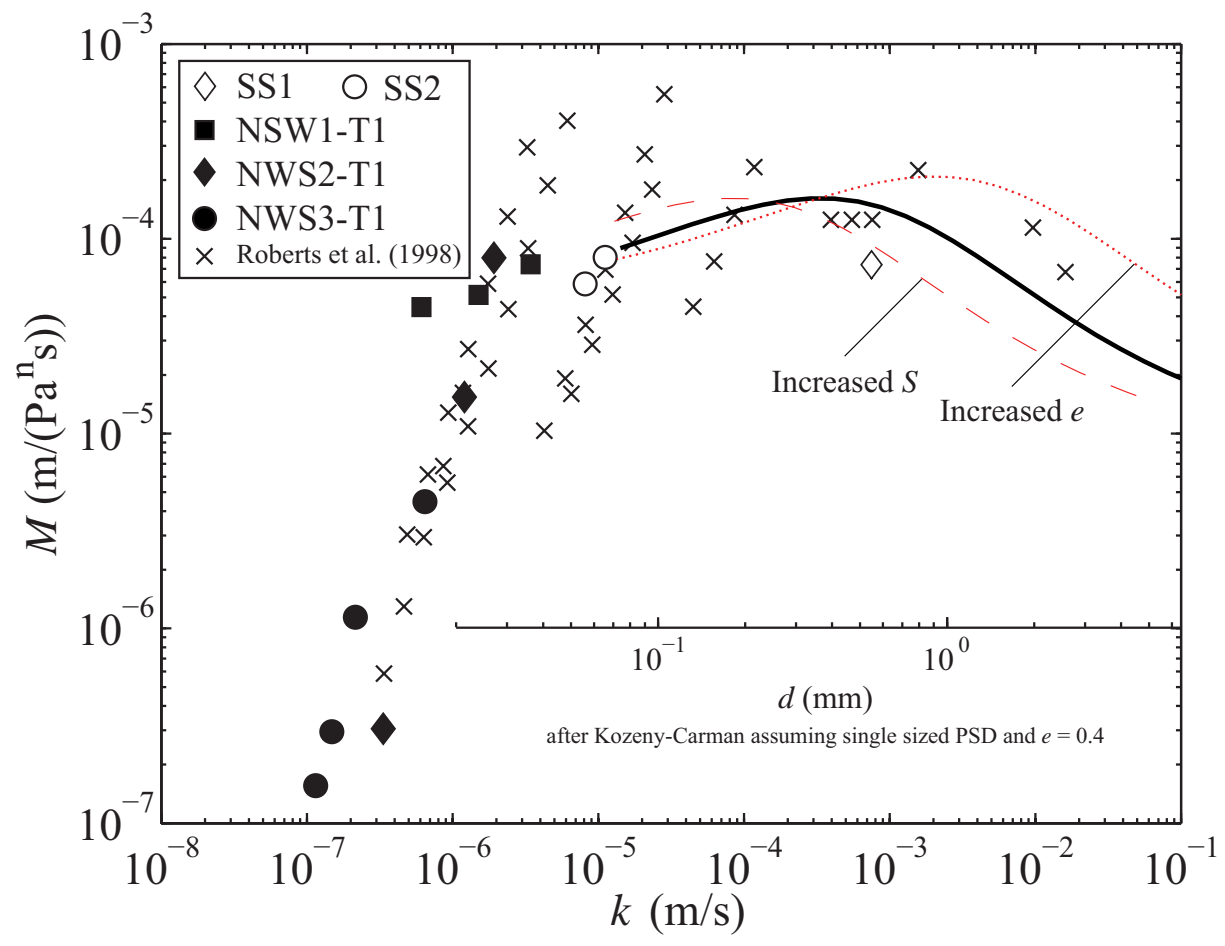

FIG. 12: Erosion parameter $M$ as a function of permeability. Plotted results for NWS1-T1, NWS2-T1, NWS3-T1, SS2 and SS2 are based on permeability estimates based on Rowe Cell tests. Also shown is reinterpreted data from Roberts et al. (1998). The lines were obtained from an interpretation of Yalin's formula and the Kozeny-Carman equation. $M$ was obtained using least squares fitting to Yalin's transport formula assuming threshold shear stresses from the Shields curve and a sample length of $150 \mathrm{~mm}$. The black line represents a single sized sediment with $e=0.4$, the dotted line shows a loose sand $(e=0.8)$ for a single sized sediment and the dashed line represents a sediment with $e=0.4$ and a doubled specific surface compared to a single sized sediment. 


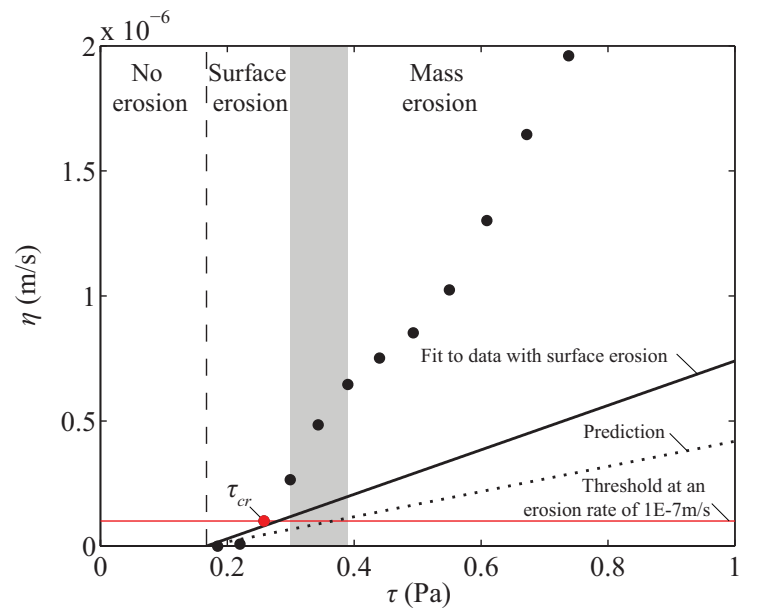

(a) NWS3-T1 with $\rho_{\text {bulk }}=1624 \mathrm{~kg} / \mathrm{m}^{3}$

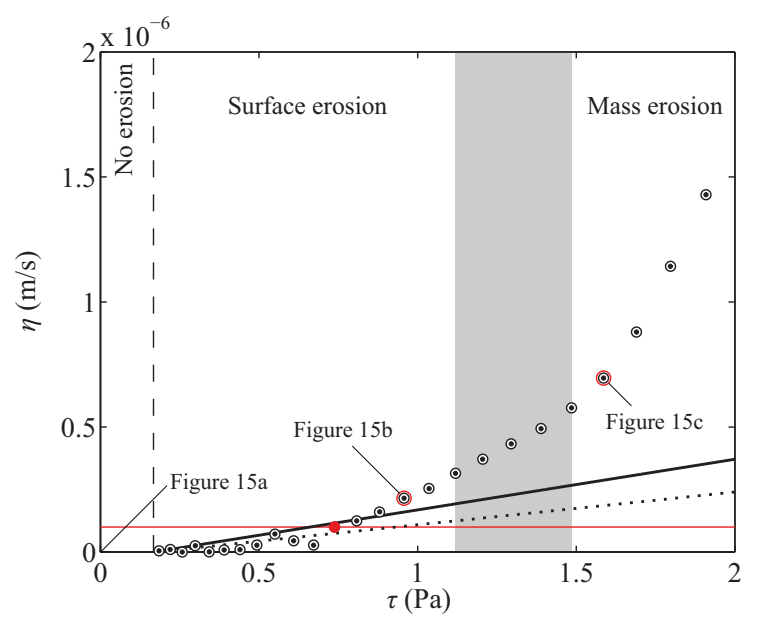

(c) NWS3-T1 with $\rho_{\text {bulk }}=1715 \mathrm{~kg} / \mathrm{m}^{3}$

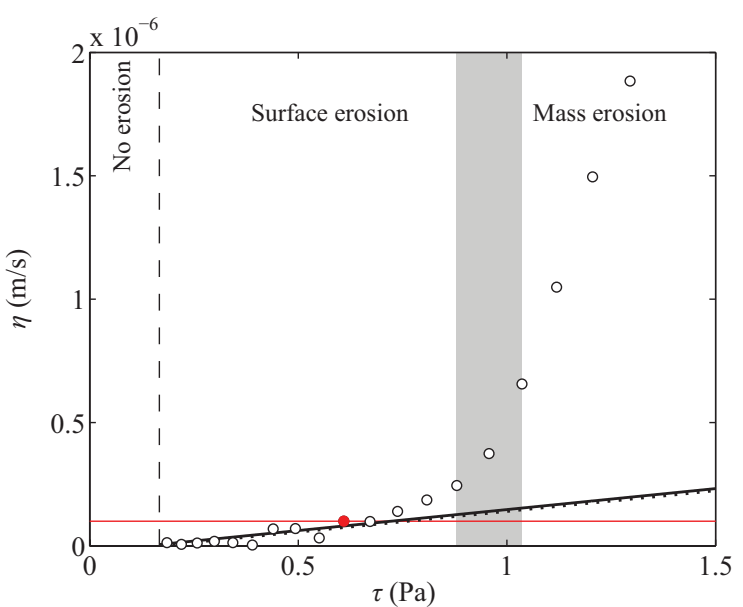

(b) NWS3-T1 with $\rho_{\text {bulk }}=1691 \mathrm{~kg} / \mathrm{m}^{3}$

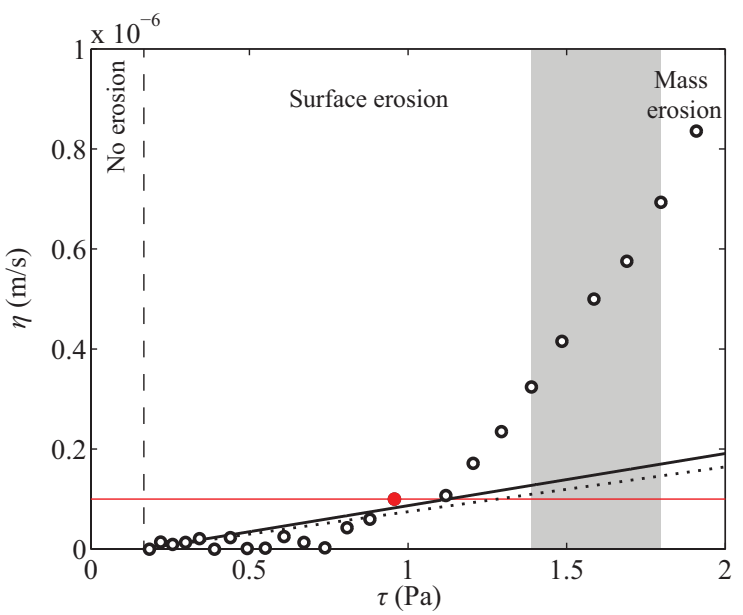

(d) NWS3-T1 with $\rho_{\text {bulk }}=1757 \mathrm{~kg} / \mathrm{m}^{3}$

FIG. 13: Erosion rate measurements for the sediment NWS3-T1 for different densities showing the initial erosion rate against predicted value from Equation (10). 


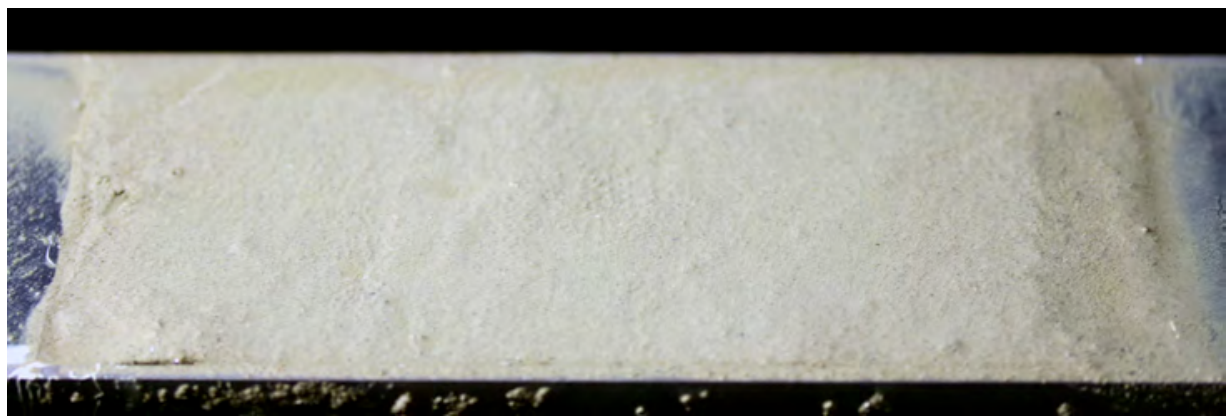

(a) Prepared sample before erosion.

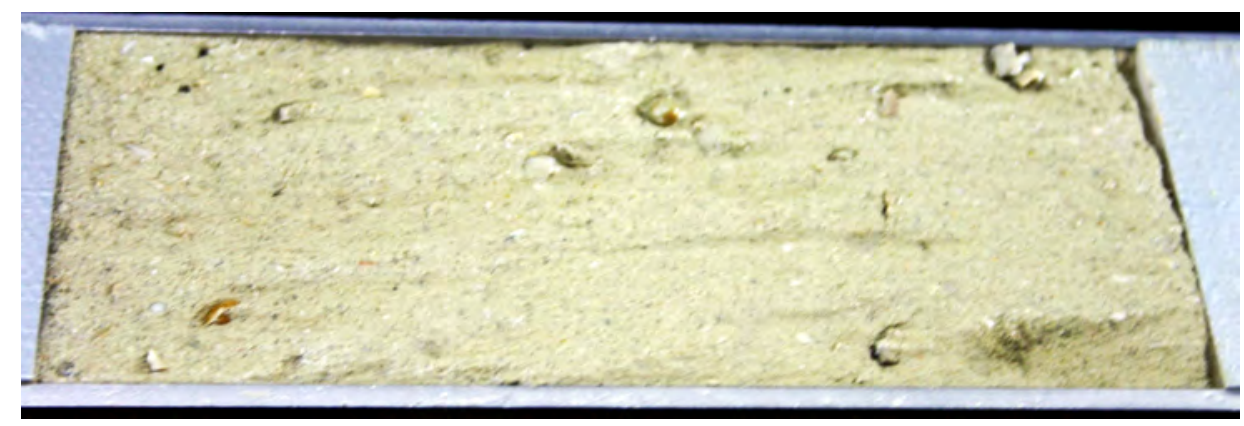

(b) Eroded sample at a density of $1715 \mathrm{~kg} / \mathrm{m}^{3}$ with a constant shear stress at $\sim 1.3$ times the threshold showing mainly artefacts of surface erosion.

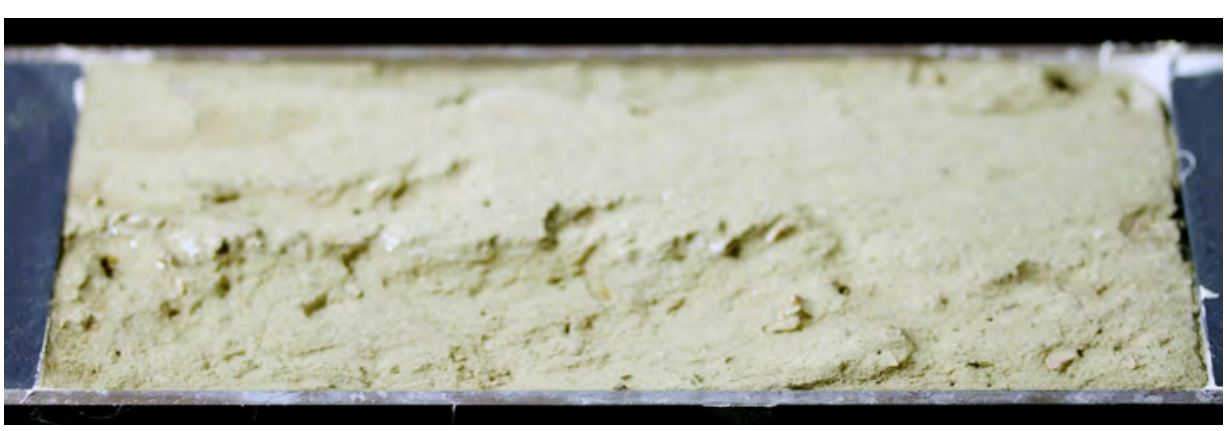

(c) Eroded sample at a density of $1707 \mathrm{~kg} / \mathrm{m}^{3}$ with a constant shear stress at $\sim 2.3$ times the threshold showing mainly artefacts of mass erosion.

FIG. 14: NWS3-T1 sediment sample before and after erosion testing exhibiting a threshold shear stress $\left(\tau_{\text {cr }}\right)$ of $\sim 0.74 \mathrm{~Pa}$. The flow is from left to right. For each photograph, the respective shear stress is indicated in Figure 13(c) which shows the erosion curves for NWS3-T1 with similar density. 


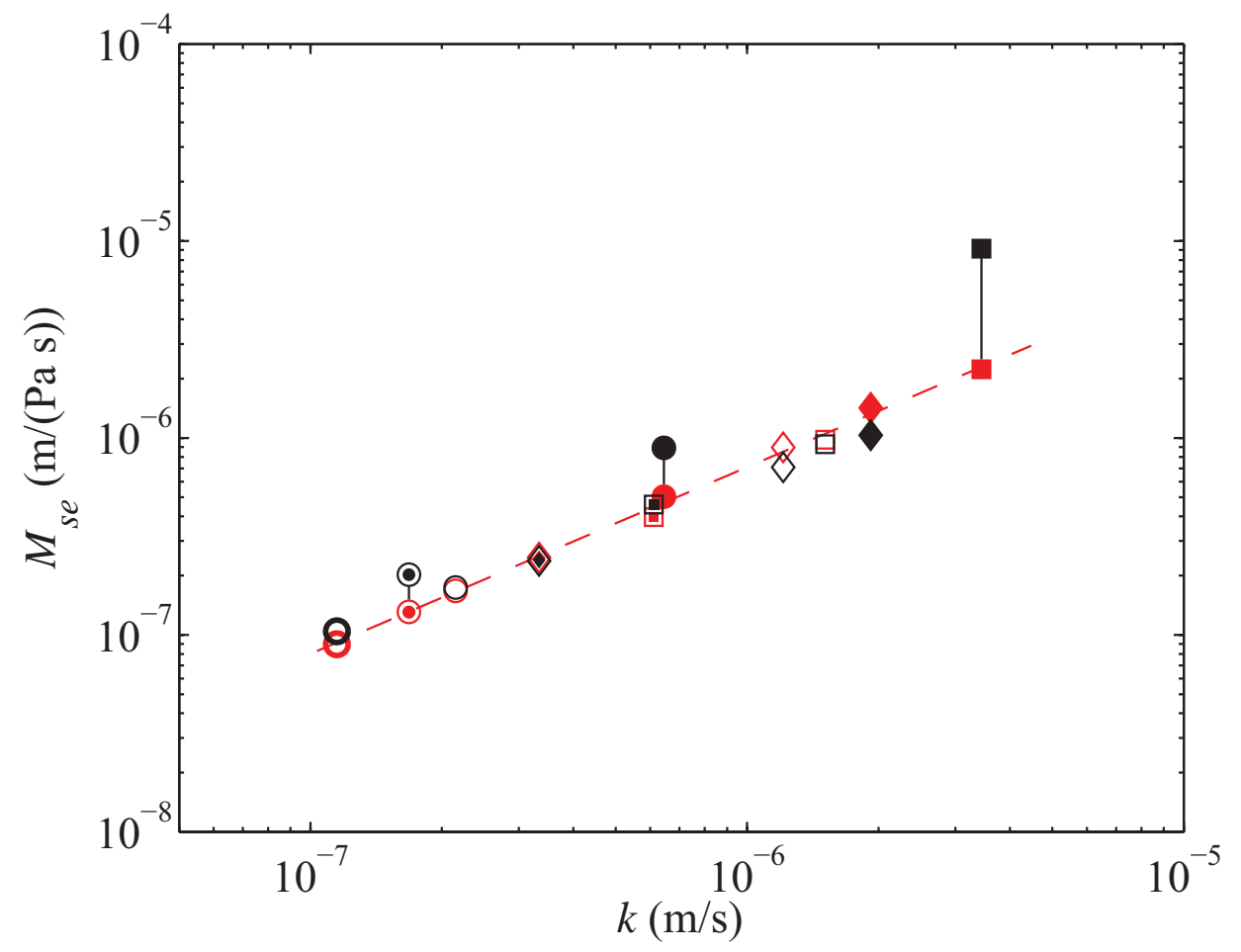

FIG. 15: Comparison of the fitted initial erosion gradient in black with predicted values in red based on Equation (10). Square symbols are NWS1-T1, diamond symbols are NWS2-T1 and circle symbols are NWS3-T1. 